\title{
Reconstrucción de un flujo de derrubios: el desastre de Marines (Valencia) de octubre de 1957
}

Reconstruction of a debris flow: the disaster of Marines (Valencia) of October 1957

\author{
Carles Sanchis Ibor \\ csanchis@hma.upv.es \\ Centro Valenciano de Estudios del Riego \\ Universitat Politècnica de València (España) \\ Joan F. Mateu Bellés \\ juan.mateu@uv.es \\ Almudena Rozalén García \\ almudenaroga@gmail.com \\ Departamento de Geografía \\ Universitat de València (España)
}

\section{Resumen}

En la mañana del 14 de octubre de 1957 una masa compuesta principalmente por bloques y fango procedente de la vertiente oeste de las crestas del Rodeno (Sierra Calderona) asoló la mayor parte del casco urbano de Marines (Valencia), causando 6 víctimas mortales y numerosos 
daños materiales. A partir de la consulta de documentación de archivo, de la revisión de diversas fotografías, del examen de los depósitos sedimentarios y de los testimonios de algunos supervivientes, este trabajo ensaya una reconstrucción del episodio y una interpretación geomorfológica del movimiento de masa. Los materiales analizados han permitido elaborar una cartografía detallada de los procesos y formas del evento e identificarlo como un flujo de derrubios posiblemente conectado a avalanchas en zonas de cabecera. La magnitud del suceso y la presencia de depósitos similares en las inmediaciones ponen de relieve la elevada peligrosidad que subsiste en este núcleo de población.

Palabras clave: geomorfología de laderas; riesgos naturales; movimientos de masa; flujo de derrubios; precipitaciones torrenciales.

\section{Abstract}

On the morning of 14th October 1956, a mass made of boulders and mud fall through the slope of the Rodeno Mountain (Calderona range) and destroyed part of the urban area of Marines (Valencia), causing 6 fatalities and numerous material damages. This research reconstructs this event and develops an interpretation of the mass movement, based on documents from historical archives, post-event pictures, interviews with witnesses and sediment examination. These materials allow mapping the event and identifying this phenomenon as a debris flow most likely connected to initial debris avalanches that took place at the headwaters area. The magnitude of the event and the existence of similar sediment deposits in the surrounding area highlight the significant hazard that still threatens this mountain village.

Key words: slope geomorphology; natural hazards; landslides; debris flow; torrential rainfall.

\section{Introducción}

El temporal de lluvias del 12 al 14 de octubre de 1957 ha quedado grabado en la memoria de muchos españoles por el impacto de la crecida del río Turia que asoló la ciudad de Valencia. La magnitud del desbordamiento del río, la afección sobre infraestructuras y personas, y su influencia sobre la posterior configuración del área urbana han merecido la atención de diversos especialistas (Carmona, 1997; Mateu et al., 2012; Portugués et al., 2016). Aquel temporal, no obstante, también afectó de manera severa a otras localidades ribereñas del Turia y a diversos lugares de la fachada mediterránea de la península (Olcina Cantos, 1999). En esta relación de espacios damnificados por el temporal hemos de incluir Marines (Valencia), una localidad 
enclavada en la Sierra Calderona cuyo casco urbano (Figura 1) fue parcialmente destruido por un movimiento de masa durante la mañana del 14 de octubre de 1957.

Este desastre quedó a la sombra de los sucesos de la ciudad y apenas mereció la atención de los medios de comunicación de la época, que refirieron de manera sucinta el recuento de víctimas, daños materiales y algunas de las acciones de auxilio efectuadas por civiles y militares españoles, y por miembros del cuerpo de marines de los Estados Unidos (Las Provincias, 1957a, 1957b; Levante, 1957a, 1957b). Pasados 63 años, el episodio tampoco ha captado el interés de los investigadores, y solo algunas publicaciones históricas locales lo describen brevemente (Deltoro 2002; Soler \& Yago, 2004). Otros trabajos mencionan el movimiento de masa con la finalidad de exponer las causas que motivaron el traslado de la población a la partida de la Maimona (Llíria), tras la intervención del Instituto Nacional de Colonización (Hermosilla \& Rodrigo, 1997). La localización de un expediente elaborado por la administración local en el Archivo Diocesano de Valencia, por parte de uno de los autores de este texto, abrió la puerta a una investigación que ha perseguido como objetivo la reconstrucción del evento y su análisis geomorfológico, mediante el examen de otras fuentes documentales y orales, y el reconocimiento de los depósitos generados por este episodio y por sucesos similares acaecidos en las inmediaciones.

Los flujos de derrubios (debris flows) son fenómenos relativamente frecuentes en zonas de montaña. Han sido estudiados, catalogados y clasificados en diversos ámbitos climáticos y litológicos y con demasiada frecuencia han afectado severamente a infraestructuras y asentamientos humanos en la cuenca mediterránea (White et al., 1998; Benito et al., 1998; Santangelo et al., 2011; Del Ventisette et al., 2012). Es precisamente en estos casos donde la investigación se hace más necesaria, con objeto de evaluar peligrosidades y planificar actuaciones para la protección y defensa de los asentamientos humanos. Este es el fin último del presente trabajo, que además se centra en un ámbito donde se han efectuado pocos trabajos sobre estos fenómenos (Surió \& Cano, 1981; Harvey, 1984; Segura, 2003; Giménez Font, 2006). 
Figura 1. Localización del área de estudio
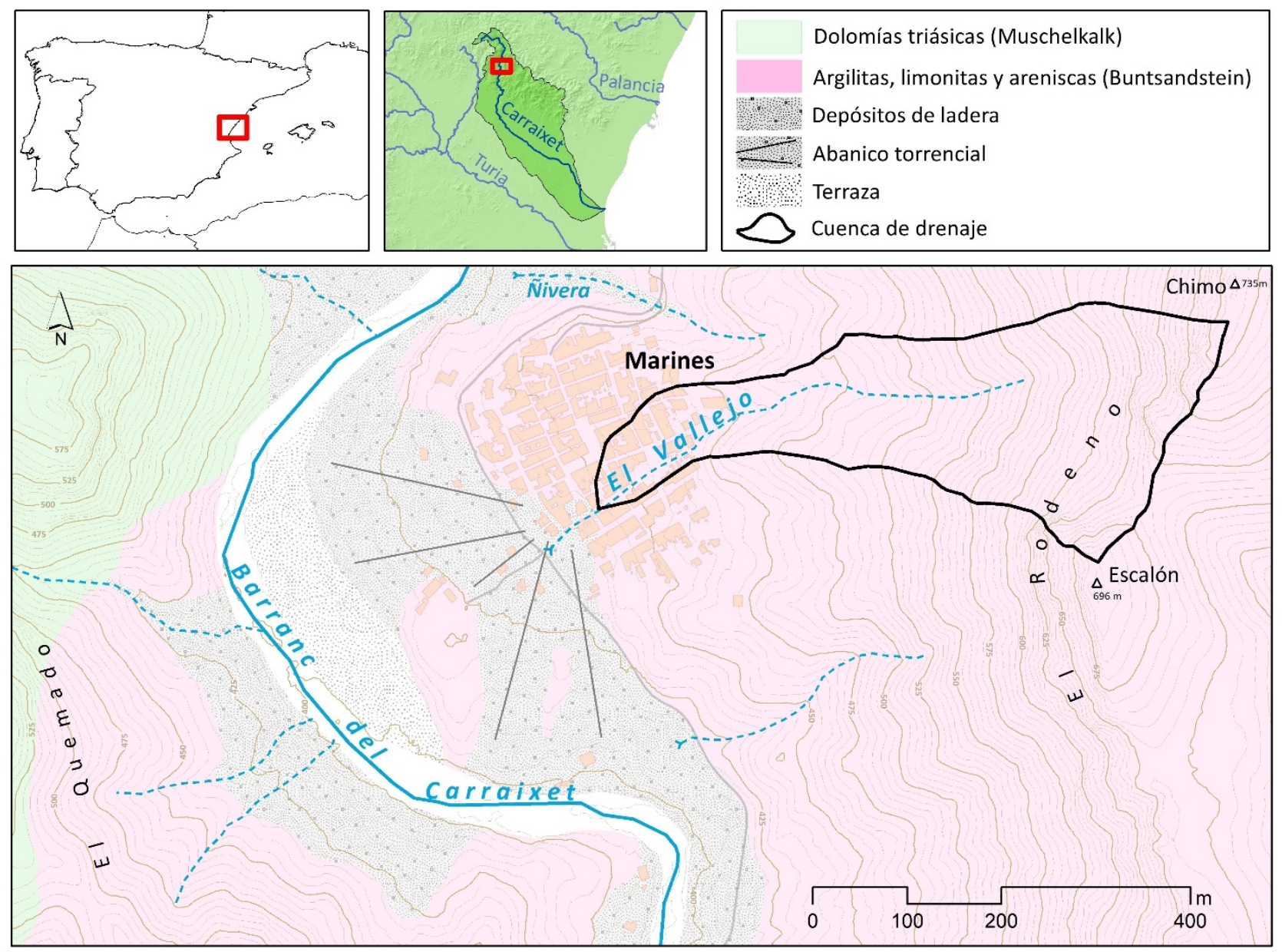

Fuente: laboración propia a partir de la cartografía oficial de la Comunitat Valenciana a escala 1:5.000 en formato shape del Institut Cartogràfic Valencià y del modelo de elevación del terreno de 100 metros de resolución de la Comunitat Valenciana del Institut Cartogràfic Valencià

\section{El estudio de los flujos de derrubios}

La intensidad y la recurrencia de los flujos de derrubios ha sido permanentemente un estímulo para su estudio. No en vano, los primeros trabajos de recopilación de eventos históricos y la teoría sobre los abanicos torrenciales surgen en los Alpes, donde las tormentas estivales otorgan una frecuencia casi anual a este tipo de fenómenos y a otros flujos y deslizamientos similares. A principios del siglo XX, Mougin (1914) registró 245 episodios históricos de flujos rápidos de diversos tipos en los torrentes de Saboya y poco después Lütsch (1926) contabilizó más de 300 en el cantón suizo de Wallis. Estos trabajos abrieron el camino a otros muchos inventarios en este y otros sistemas montañosos, la mayoría de los cuales han sido referidos, ya en el presente siglo, por Tropeano y Turconi (2004). Mucho antes, Surrell (1841) había establecido la 
vinculación entre estos flujos torrenciales y sus formas asociadas -cuenca, canal y cono de deyección-, proponiendo el modelo hidrogeomorfológico del torrente alpino, difundido en España por Madrazo (1861) e Inchaurrandieta (1868) (Mateu, 2018). Algunas publicaciones de este periodo ya evalúan la incidencia de variables morfométricas clave como el tamaño de la cuenca y el abanico, la longitud del canal y la pendiente de estas tres geoformas. No obstante, en estos trabajos pioneros resulta difícil distinguir entre los diversos tipos de flujos que acarrean sedimentos a los conos de deyección. No se efectúa una categorización específica de los flujos de derrubios. No había todavía una atención o precisión suficiente en el gradiente de densidad y la composición de la carga sólida de estos fenómenos.

La categorización de los flujos rápidos asociados a laderas y torrentes de tipo alpino es posterior en el tiempo y no se consolida hasta la segunda mitad del siglo XX, con investigaciones que establecieron clasificaciones de los movimientos de masa que hoy consideramos clásicas, como las de Varnes $(1954,1978)$ y Hutchinson (1968). Es a partir de este momento cuando se analiza con mayor detalle la singularidad de las propiedades reológicas y geomorfológicas de los flujos de derrubios (Takahashi, 1981; Costa, 1984; Iverson, 1997). Son trabajos que caracterizaron de forma precisa estos fenómenos, pero que al desarrollarse en paralelo por diferentes escuelas, en distintos territorios y con criterios independientes, no permitieron fijar una terminología común (Bradley \& McCutcheon, 1985). En este sentido, en el caso español, se observa como la tipología propuesta por Corominas (1989) difiere o modifica en algunos aspectos las clasificaciones geomorfológicas de las escuelas anglosajona y francesa.

Coussot y Meinier (1996) ensayaron una primera clasificación sintética basada en el tipo de material y la proporción de fracción sólida, definiendo los flujos de derrubios (debris flow) como un fenómeno intermedio entre los flujos hiperconcentrados y los deslizamientos de ladera (landslide), cuya propagación debía ser analizada como parte de la mecánica de fluidos noNewtonianos, en la línea de lo definido por Johnson y Rodine (1984). Hungr et al. (2001), compartiendo esta preocupación por la relativa dispersión y vaguedad terminológica en los movimientos de tipo flujo, elaboraron una tipología bastante más detallada. Establecieron una clasificación por tipos de materiales y en el caso de los derrubios -considerados como materiales heterogéneos no-cohesivos-, distinguieron entre flujos de derrubios (debris flow), avalanchas de derrubios (debris avalanche) y avenidas de derrubios (debris flood). Los primeros (debris flow) se definen como flujos saturados muy rápidos de derrubios no plásticos en canales de pendiente pronunciada. Las avenidas de derrubios, equiparadas con lo que algunos autores denominan flujos hiperconcentrados, se distinguieron de los flujos de derrubios por la 
concentración de la carga, <80\% según Costa (1984). Por su parte, las avalanchas de derrubios, a diferencia de los anteriores, se han definido como flujos someros parcial o completamente saturados, con la particularidad de no presentar confinamiento en canal alguno.

Debido a la naturaleza transitoria y cambiante de estos fenómenos, Hungr et al. (2001) han argumentado que esta distinción no puede tener un carácter taxonómico. Un mismo evento puede comenzar como una avalancha de derrubios y convertirse en un flujo de derrubios al llegar o al generar un canal, de la misma manera que en un mismo episodio, una avenida de derrubios puede devenir un flujo, o tramos de una corriente con características predominantes de flujo de derrubios pueden presentar puntualmente la carga sólida propia de una avenida de derrubios. Takahashi (2001, 2009) ya había reparado en estas circunstancias en sus numerosos trabajos -treinta propios se citan en su revisión de la cuestión en Japón-, y elaboró un modelo explicativo en el que detallaba la transición entre un deslizamiento inicial -correspondiente o no con la avalancha de derrubios de Hungr et al. 2001- y el posterior flujo de derrubios, a partir del examen de sus propiedades reológicas. Los trabajos de Takahashi (2009) también analizaron cuantitativamente las transiciones que se establecen entre un flujo inicial de agua y su posterior transformación en un flujo de derrubios con la movilización de un volumen importante de carga sedimentaria. Estas variaciones en la composición de los flujos se han contrastado en la Península Ibérica y resultan una pieza clave de la conectividad hidráulica entre laderas y cauces (Gómez-Villar et al., 2014).

Con independencia de las propiedades reológicas que explican el inicio y desarrollo del flujo de derrubios, existen una serie de condiciones y factores que favorecen de forma notoria estos fenómenos y que ya fueron bien identificados por los trabajos más pioneros (Mateu, 2018). Lluvias torrenciales o fusión nival, fuertes pendientes, deforestación o debilidad de la cubierta vegetal y presencia de litologías poco cohesivas (o alternancia de estratos de diferente consistencia) han sido repetidamente señalados como catalizadores de estos fenómenos. En la Península lbérica, diversos trabajos han contrastado la incidencia de estos factores. Respecto a las Iluvias torrenciales, García Ruiz et al. (1988, 2013) establecieron un umbral de torrencialidad para la activación de estos procesos, a partir del estudio del caso del río Najerilla, el cual se reduce notablemente en las áreas afectadas por incendios forestales. Otros autores han destacado y cuantificado la importancia de la lluvia antecedente (Pereida \& Zêzere, 2012). La pendiente no sólo se ha considerado como un factor de activación de estos procesos, sino que además, presenta una correlación significativamente positiva con el tamaño de las partículas movilizadas (Gómez-Villar, 2014). La incidencia de los procesos de degradación de la cubierta 
vegetal ha sido analizada principalmente en las últimas décadas, prestándose particular atención a la afección generada por diferentes actividades antrópicas (Lasanta et al., 2006, Beguería et al., 2006). En relación a las litologías blandas o alternas, es particularmente interesante el contraste observado en los Pirineos entre las zonas con predominio de facies Flysch, mucho más proclives al desarrollo de estos movimientos de masa, y otros sectores de la cordillera (MartínezCastroviejo \& García-Ruiz, 1990; Lorente et al. 2002). Además, algunos trabajos cuantifican el efecto de estos factores mediante la elaboración de modelos que se han aplicado a la generación de mapas de peligrosidad (Carrasco et al., 2003; Pedraza et al., 2004)

En las últimas décadas, a los enfoques tradicionales de estudio, basados en el reconocimiento geomorfológico, el estudio de las propiedades físicas del flujo y el análisis de la estratigrafía de los depósitos, se han incorporado con éxito los Sistemas de Información Geográfica (Cavalli et al., 2017) y los análisis dendrogeomorfológicos (Procter et al., 2012; García-Oteyza et al., 2015). Al mismo tiempo, se han generalizado los métodos de monitorización, principalmente a través del seguimiento por video y diferentes sensores de movimiento (Berti et al., 1999; Arattano \& Marchi, 2008; Hürliman et al., 2014). Estas técnicas vienen a completar las metodologías clásicas de observación post-crecida, que aportan un importante caudal de datos cuando se emplean con posterioridad inmediata al suceso, pero que se hacen más complejas cuando se trata de procesar la información fragmentaria e imprecisa de los eventos históricos (Barkinel, 2004). El inventario y reconstrucción de episodios históricos es determinante para poder avanzar en el conocimiento y prevención de estos fenómenos, más cuando se dispone de suficiente material gráfico, de informes técnicos de cierto rigor y de testigos del suceso. Esta información en muchos casos debe permitir cartografiar el área afectada, reconocer el tipo de flujo, caracterizar el desarrollo del movimiento de masa y los procesos asociados y, cuando se dispone de elementos de calibración, efectuar una evaluación cuantitativa a través de ecuaciones empíricas (Marchi \& Cavalli, 2007).

\section{Fuentes y métodos de estudio}

Para la reconstrucción del desastre de Marines se ha recurrido a diversas fuentes, a fin de delimitar el área afectada, localizar procesos y formas asociadas al movimiento de masa, identificar el tipo de flujo y analizar los factores que motivaron o condicionaron su desarrollo. Para ello se ha recurrido a información conservada en el Archivo Diocesano de Valencia (ADV), el Archivo Municipal de Marines (AMM) y el Archivo de la Diputación Provincial de Valencia (ADPV), en los que se conservan informes elaborados por la administración con posterioridad al 
suceso y otras fuentes documentales que aportaron información más tangencial. Debe resaltarse que no se ha hallado documentación asociada a trámites administrativos directamente relacionados con el evento, sino que ésta aparece siempre relacionada a las gestiones desarrolladas posteriormente para justificar el traslado de la población a un nuevo emplazamiento

Además, se ha podido entrevistar a 9 personas, 8 de las cuales fueron testigos directos del movimiento de masa o de sus consecuencias inmediatas, mientras que otra relató la información transmitida por su padre. Entre ellos hay 6 mujeres y 3 hombres, que tenían entre 67 y 92 años de edad en el momento de la entrevista (invierno de 2018). Su localización durante la catástrofe se muestra en la Figura 2.

La información más valiosa para este trabajo ha sido el conjunto de fotografías asociado a estos documentos, principalmente las 29 imágenes adjuntas al informe redactado por Enrique Cortell, alcalde de Marines, depositado en el ADV. No ha sido posible identificar al autor de todas las imágenes de este documento, pero algunas de ellas fueron tomadas por Luis Vidal el 18 de octubre, que publicó 3 en el diario Levante el día 19 (Levante, 1957b). Estas 3 y otras 4 de autor desconocido, se conservan en copias de gran calidad en el expediente de segregación de los términos de Llíria y Olocau para la construcción del nuevo casco urbano, custodiado en el AMM. Todas ellas parecen también hechas muy pocos días después de la tragedia. Otro grupo de 8 imágenes de una calidad extraordinaria completan este conjunto. Fueron tomadas por Julián Romero Cortell y han sido facilitadas por Pilar Cortell Sánchez. Estas parecen haber sido captadas algunos días más tarde, pues en determinados lugares se observa que el sedimento que había bloqueado las calles ya había sido retirado. A estas deben añadirse 4 vistas generales del pueblo tomadas por este mismo fotógrafo en julio de 1956, agosto de 1957, noviembre de 1957 y julio de 1960. La Figura 2 muestra la localización del punto de toma de imágenes postevento, que ha sido posible tras un exhaustivo proceso de revisión y localización de diversos hitos reconocibles en varias fotografías, ya que alguna de ellas llevaba adjuntas anotaciones de localización que resultaron erróneas y dificultaron las etapas iniciales de la investigación.

Las fuentes orales y documentales, junto con el reconocimiento de los depósitos conservados, han servido para elaborar una cartografía de procesos y formas mediante ArcGis 10.2 (ESRI, Redlands). Este software ha sido empleado también para analizar las imágenes aéreas del vuelo americano de 1957, que han permitido reconocer el estado de la cubierta vegetal en el momento anterior al movimiento de masa, y para integrar el modelo digital de elevación con 
paso de malla de 5 metros obtenido a partir de los datos LiDAR de 2009 y 2010 procesados por el Centro Nacional de Información Geográfica. Estos materiales y los trabajos de campo han sido determinantes para reconocer un espacio que la escala de la cartografía geológica oficial no permitía caracterizar con suficiente precisión.

Figura 2. Localización y número de inventario de las fotografías efectuadas con posterioridad al evento (en blanco) y del lugar de residencia de los testigos (en naranja)

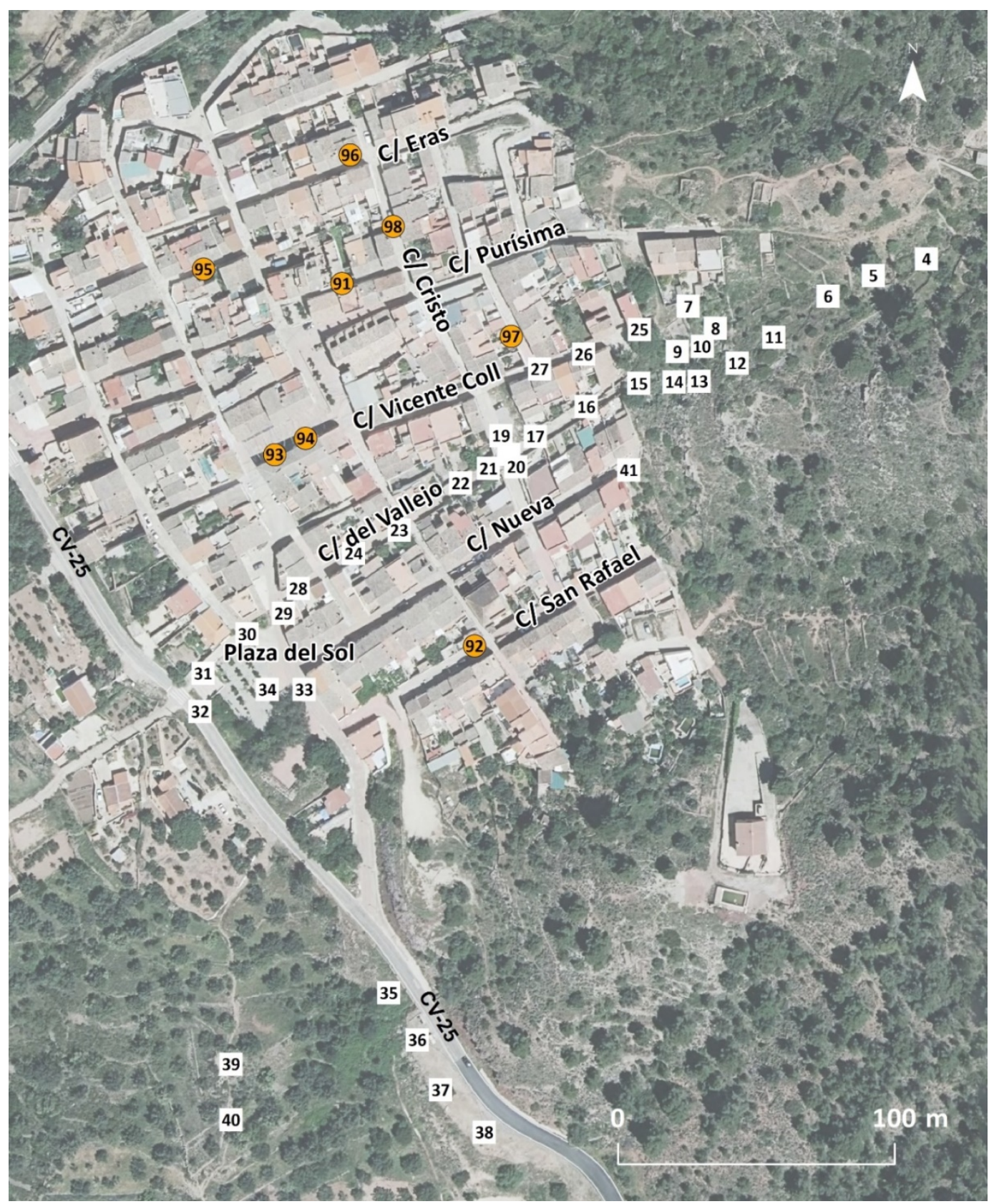

Nota: No se incluyen las fotografías 1, 2 y 3, tomadas desde la cumbre del Chimo y el Escalón y las cuatro vistas generales tomadas desde posiciones alejadas por Julián Romero.

Fuente: Elaboración propia a partir de ortofoto de 2019 de la Comunitat Valenciana a escala 1:5.000 del Institut Cartogràfic Valencià 


\section{Marines en 1957. Contexto geográfico del evento}

El núcleo histórico de Marines, hoy conocido como Marines Viejo o Colonia la Marinense, se halla enclavado en el corazón de la Sierra Calderona. Esta alineación montañosa, perteneciente al sector oriental de la Cordillera Ibérica (Pérez Cueva, 1985; Garay, 2001), arranca a pocos kilómetros del mar. Sus cumbres parten de la abrupta atalaya litoral del Picaio (373 m snm) y van ganado altura hacia el interior, hasta conectar con el Macizo de Javalambre (2020 m snm). La sierra presenta un predominio de litologías triásicas, con laderas de mayor pendiente e inestabilidad sobre los materiales silíceos (Calvo, 1987), y unas precipitaciones medias anuales de entre 514 mm (Gilet) y 630 mm (Cova Santa), con un claro máximo otoñal.

Marines tiene su origen en una alquería islámica (Soler \& Yago, 2004) ubicada en la ladera del monte Rodeno, en un resalte entre los barrancos de Nivera y el Vallejo. Ambos son tributarios del barranco del Carraixet, el cual drena $314 \mathrm{~km}^{2}$ de la vertiente meridional de la Sierra Calderona (Camarasa, 1992). Marines fue un núcleo de muy pequeño tamaño (22 familias en 1660), que creció significativamente durante los siglos XVIII y XIX. Amplió entonces su casco urbano sobre el Vallejo y más allá de este, creando una trama urbana de alineaciones perpendiculares a las curvas de nivel. Tras alcanzar un máximo poblacional en 1910 (945 habitantes), la filoxera y la gripe de 1918 marcan el inicio de una etapa de decadencia. En 1956, Marines había perdido casi un tercio de su población. Contaba solo con 665 habitantes.

El monte del Rodeno se levanta 300 m por encima del campanario del pueblo. Está coronado por una imponente crestería de areniscas rojas de facies Buntsandstein, de más de $50 \mathrm{~m}$ de altura. Este escarpe, de acusada verticalidad e inestabilidad, queda interrumpido por un pequeño paso, el Colladico del Tio Chimo, entre los picos del mismo nombre (Chimo, 735 msnm) y el Escalón (696 msnm)(Figura 1). Está compuesto por una secuencia homogénea de areniscas silíceas (cuarzoarenitas), que Garay-Martín (2005) ha descrito como la formación de areniscas del Garbí. El cantil de areniscas se apoya sobre materiales mucho más blandos: depósitos de lutitas rojas con frecuentes intercalaciones de areniscas rojas o grises (facies saxoniense) que dan lugar a la formación denominada lutitas de Marines (Garay-Martín, 2005). Esta formación presenta un espesor cercano a los 300 m y llega hasta el mismo barranco del Carraixet, al pie de la ladera.

De la base del farallón rocoso parten diversos barrancos que descienden hacía el pueblo con una fuerte pendiente (51\%), atravesando los estratos alternos de argilitas y areniscas cubiertos por pequeños depósitos de ladera. Las cárcavas convergen a media ladera, formando el 
barranco del Vallejo, que daba nombre a la calle por la que discurría, pero que oficialmente se conocía como calle de las Delicias (Figura 2). La cuenca del Vallejo apenas se extiende sobre 9'1 ha, pero presenta una pendiente media del $32,1 \%$, en consonancia con lo observado en otras laderas silíceas de la región (Calvo, 1987). En 1957 las faldas del Rodeno estaban desprovistas de vegetación de porte arbustivo y arbóreo, que era consumida como leña en el pueblo. Sólo en la zona más abrupta, junto a las crestas, subsistían algunos pinos y alcornoques. Un matorral ralo, acompañado de herbáceas, cubría la mayor parte de esta empinada vertiente, cuya parte más baja estaba escalonada por bancales de muy pequeñas dimensiones, buena parte de ellos ya abandonados por la despoblación (Figura 3). Hoy día, la vegetación cubre casi por completo la ladera, tras un proceso de regeneración espontánea que domina el Pinus halepensis, acompañado por buena parte del cortejo de la variante continental o meridional del alcornocal valenciano (Asplenio onopteridis-Quercerum suberis, Costa et al., 1985, quercetosum rotundifoliae, García-Fayos, 1991).

El pequeño curso efímero del Vallejo da lugar a un amplio abanico torrencial, cuyo ápice se sitúa en el mismo pueblo. Presenta una pendiente del $13 \%$ y se prolonga hasta el cauce del barranco del Carraixet, el cual describe un pronunciado meandro, perfectamente ajustado a la curvatura de dicho cuerpo sedimentario. No obstante, la forma de este depósito está condicionada por diversos resaltes de la formación Marines, cuyas lutitas y areniscas afloran en algunos puntos, singularmente en la parte meridional (Figura 1). En 1957, la mayor parte del lóbulo central del abanico la ocupaban bancales destinados al cultivo de la viña, mientras que el sector meridional era un olivar (Figura 3). En la zona distal, el contacto con el cauce del Carraixet lo establecía una terraza baja, aprovechada para el cultivo hortícola. 
Figuras 3 y 4 . Vista de Marines en noviembre de 1957 (izquierda), poco tiempo después del flujo de derrubios
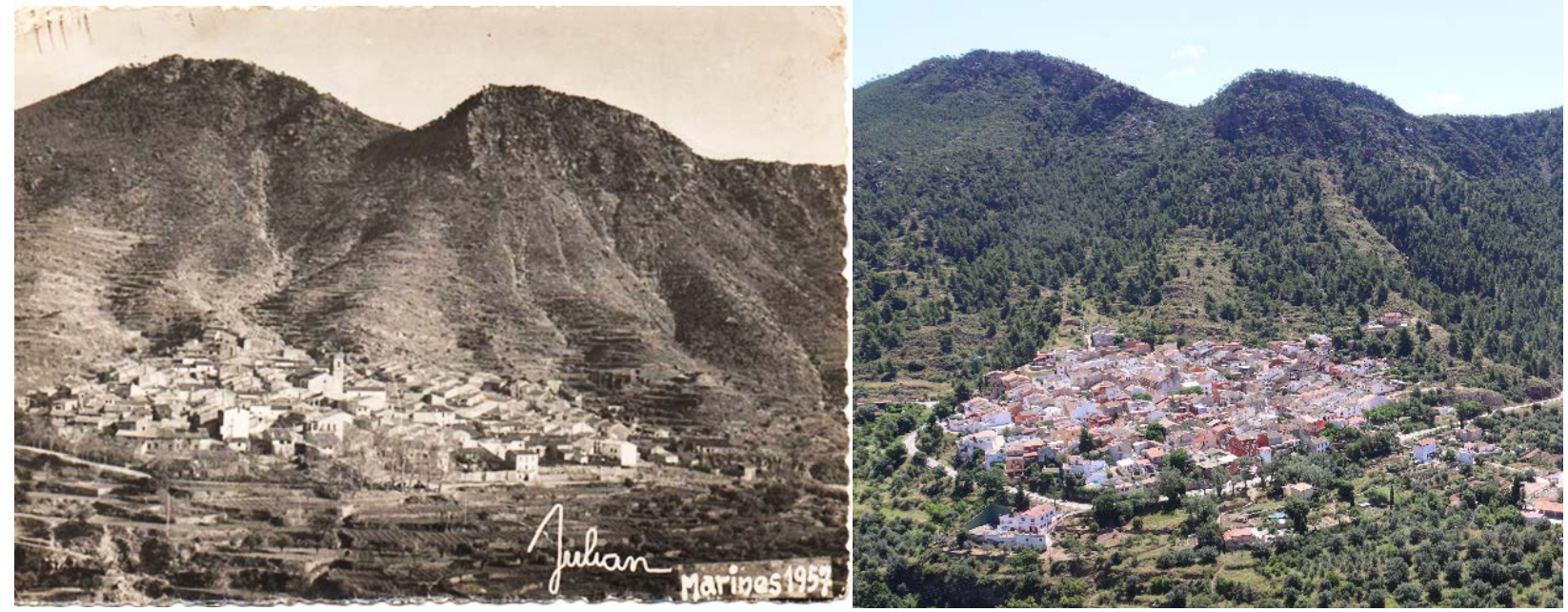

Nota: Se puede observar la escasa cubierta vegetal de la ladera del monte del Rodeno en comparación con la situación actual (derecha)

Fuente: Julián Romero (1957) (izquierda); Carles Sanchis Ibor (junio de 2020) (derecha)

\section{El temporal y la lluvia antecedente}

El catalizador del movimiento de masa que asoló Marines el 14 de octubre fue un episodio de precipitaciones torrenciales que se había iniciado 48 horas antes y que, pese a la precariedad de datos propia del periodo, fue bien caracterizado por los meteorólogos García Miralles y Carrasco (1958). El temporal fue activado por un embolsamiento de aire frío en altura coincidente con una baja anclada sobre el golfo de Cádiz. En esta posición, la baja impulsa un flujo E-SE sobre el litoral valenciano que se canaliza bien en los relieves de directriz ibérica (NW-SE), generando abundantes precipitaciones en los valles del Turia y el Palancia. No obstante, en la respuesta de la ladera del Rodeno, y en general, en la de toda la cuenca del Turia, tuvo un papel determinante un episodio de precipitaciones que sucedió diez días antes, entre el 1 y el 5 de octubre de 1957 (Marco \& Mateu, 2007). La caracterización de estos episodios en el entorno de Marines choca con la falta de datos locales. Los observatorios más próximos, Llíria y Casinos, se sitúan en el piedemonte del valle del Turia, y aunque reflejan el comportamiento de la misma célula, seguramente no recogen el efecto de disparo orográfico o la tormenta local que, a tenor de lo observado, debió producirse en Marines en la mañana del día 14.

El temporal de primeros de mes tuvo magnitud suficiente para dejar los suelos de la Sierra Calderona próximos a la saturación. Los observatorios de Casinos y Llíria registraron 87, 5 y 111 
mm entre los días 2 y 4; Altura, al pie de la vertiente norte de la Calderona, 116 mm entre los días 1 y 4; y Serra, sobre la misma alineación montañosa pero más cercana al mar 110,6 mm. Las precipitaciones fueron bastante regulares entre los distintos puntos y entre los diferentes días, por lo que podemos deducir que sobre Marines debió caer una lluvia ligeramente superior a los 100 mm. Dado que, como indican Camarasa y Segura (2001), los suelos de las cuencas de la región muestran condiciones de saturación y un umbral de la escorrentía a partir de los 60 mm, se puede asumir que esta lluvia antecedente tuvo un papel crítico en el desarrollo de la escorrentía de crecida y los movimientos de masa durante el episodio del 12 al 15 de octubre.

Por consiguiente, cuando pasada una semana volvió la lluvia, la saturación de los suelos se alcanzaría muy fácilmente. En Altura, de hecho, las precipitaciones comenzaron ya el día 10, y se acumularon 55 mm antes del día 14, en el que se registraron 200 mm. Casinos y Llíria sólo cayeron $11 \mathrm{~mm}$ el día 13, pero $200 \mathrm{~mm}$ y $225 \mathrm{~mm}$ respectivamente durante el día 14. Hacía la costa las precipitaciones fueron más moderadas. En Serra registraron 45,7 mm los días 12 y 13 y $119,5 \mathrm{~mm}$ el 14 de octubre. Otros puntos de la cuenca del Turia relativamente próximos, como el Pla de Quart o Domeño, recibieron precipitaciones significativamente superiores (288 mm y $300 \mathrm{~mm}$ respectivamente), por lo que no podemos descartar que en Marines se superaran sobradamente los valores de Llíria y Casinos. De hecho, durante este temporal se registraron precipitaciones acumuladas que alcanzaron 370 mm en Begís (Castellón), 852 mm en el embalse del Buseo (Valencia) y $850 \mathrm{~mm}$ en Puebla de Valverde (Teruel). Si además consideramos que el caudal máximo vehiculado por el Carraixet alcanzó los 1300 m³ $/ \mathrm{s}$ (Cánovas, 1958), es más que probable que se rebasaran las cifras de los observatorios más próximos a la sierra.

Las precipitaciones sobre Marines, según los entrevistados, comenzaron durante la tarde del día 12 y se prolongaron con una intensidad creciente durante el día 13. En la mañana del día 14, sobre las 10:30 aproximadamente, los testigos narran que el cielo se oscureció y la lluvia arreció, acompañada de un importante aparato eléctrico (Entrevistas 1 y 4). Esta tormenta fue la que activó el movimiento de masa. Sobre las 12 comenzó a discurrir un volumen creciente de agua y barro por el Vallejo, que obligó a los vecinos de la calle del Vallejo a reforzar los portones de casas y corrales. Súbitamente, a las 12:15 horas la carga sólida se multiplicó y el flujo de derrubios alcanzó la población asolando varios edificios. ${ }^{1}$

1 Conocemos la hora exacta gracias al testimonio de la entrevistada $n^{\circ} 1$, quien recuerda que el reloj de pulsera de uno de los fallecidos se había parado en dicha hora. 


\section{El evento de Marines: reconstrucción del flujo de derrubios}

Los marinenses eran conscientes con anterioridad del problema generado por la inestabilidad de la ladera. Los entrevistados recuerdan que varias décadas antes, en una fecha sin precisar, un bloque de grandes dimensiones ya había alcanzado el casco urbano. Por su gran tamaño y ante la dificultad de trasladarlo, los picapedreros lo tallaron para construir un banco que quedó en la calle y que por su longitud era conocido como el Palillo. Además, el informe elaborado por Enrique Cortell (ADV, 1957) destaca que "Este espectáculo es frecuente si la lluvia humedece el monte, pero hasta ahora se limitaba a tres o cuatro piedras o a veces una sola, que eran detenidas por los pinos o los árboles en su bajada". La caída de bloques era un peligro que acechaba las construcciones del pueblo y, en consecuencia, el Ayuntamiento había incorporado a sus planes trienales de obras diversas actuaciones para impedir estos desastres, pero no contaba con fondos para financiarlos. La falta de recursos y la pobreza de muchos de sus habitantes, agravada por la catastrófica helada negra de febrero de 1956 que arrasó los cultivos arbolados del término, motivó que el consistorio solicitara, sin éxito, la adopción del pueblo por parte de la Diputación Provincial como vía de auxilio económico (ADV, 1957). Entre sus demandas a la administración provincial había una petición muy significativa, la construcción de un canal perimetral a modo de defensa frente a los flujos y movimientos de masa del monte del Rodeno.

La posibilidad de que se produjese un flujo de derrubios en momentos de precipitaciones intensas era ciertamente alta y de hecho, como relata el informe de la alcaldía "Una semana antes hubo un desprendimiento de consideración a dos kilómetros del casco urbano que produjo alarma" (ADV, 1957). La localización de este movimiento de masa anterior no ha podido ser confirmada. No obstante, la revisión de la documentación gráfica ha permitido identificar, en cuatro de las imágenes tomadas por Julián Romero, el canal de un flujo de derrubios situado a 400 metros del casco urbano (Figura 5), en la orilla opuesta del barranco del Carraixet, sobre la ladera del monte de El Quemado. ${ }^{2}$ Este atraviesa una superficie boscosa de una ladera muy pronunciada, al pie de una pequeña cresta de areniscas, para asolar posteriormente diversos bancales de olivar. No hemos podido determinar si éste se produjo el mismo día que el que afectó al pueblo, o bien si sucedió unos días antes o después. La

2 Las Provincias (1957b) da cuenta de otro movimiento de masa acaecido en la localidad serrana de Sot de Chera (a 35 km en dirección suroeste), sin causar víctimas ni daños materiales relevantes, pero que motivó que el diputado Heliodoro Collado solicitara también el traslado de esta población. 
documentación consultada y los entrevistados mencionan que la carretera CV-25, que comunica Marines con Olocau, Llíria y Valencia, estaba cortada cuando se produjo la catástrofe de Marines. El corte en la carretera fue principalmente debido a la crecida del barranco del Carraixet, pero hubo otros movimientos de masa que interrumpieron el paso en esta vía. Según la crónica del Levante (1957a), "entre Olocau y Marines hay centenares de desprendimientos que interceptan totalmente el paso por la carretera" y en los dos kilómetros anteriores a Marines de la CV-25, en la misma alineación de crestas del monte del Rodeno, hemos localizado hasta cuatro depósitos en superficie con las características texturales propias de los flujos de derrubios, pero con la información actual no podemos asegurar la cronología de estos depósitos (Figura 6).

Figura 5. Canal abierto por el movimiento de masa de la ladera de El Quemado, situado al otro lado del cauce del Carraixet

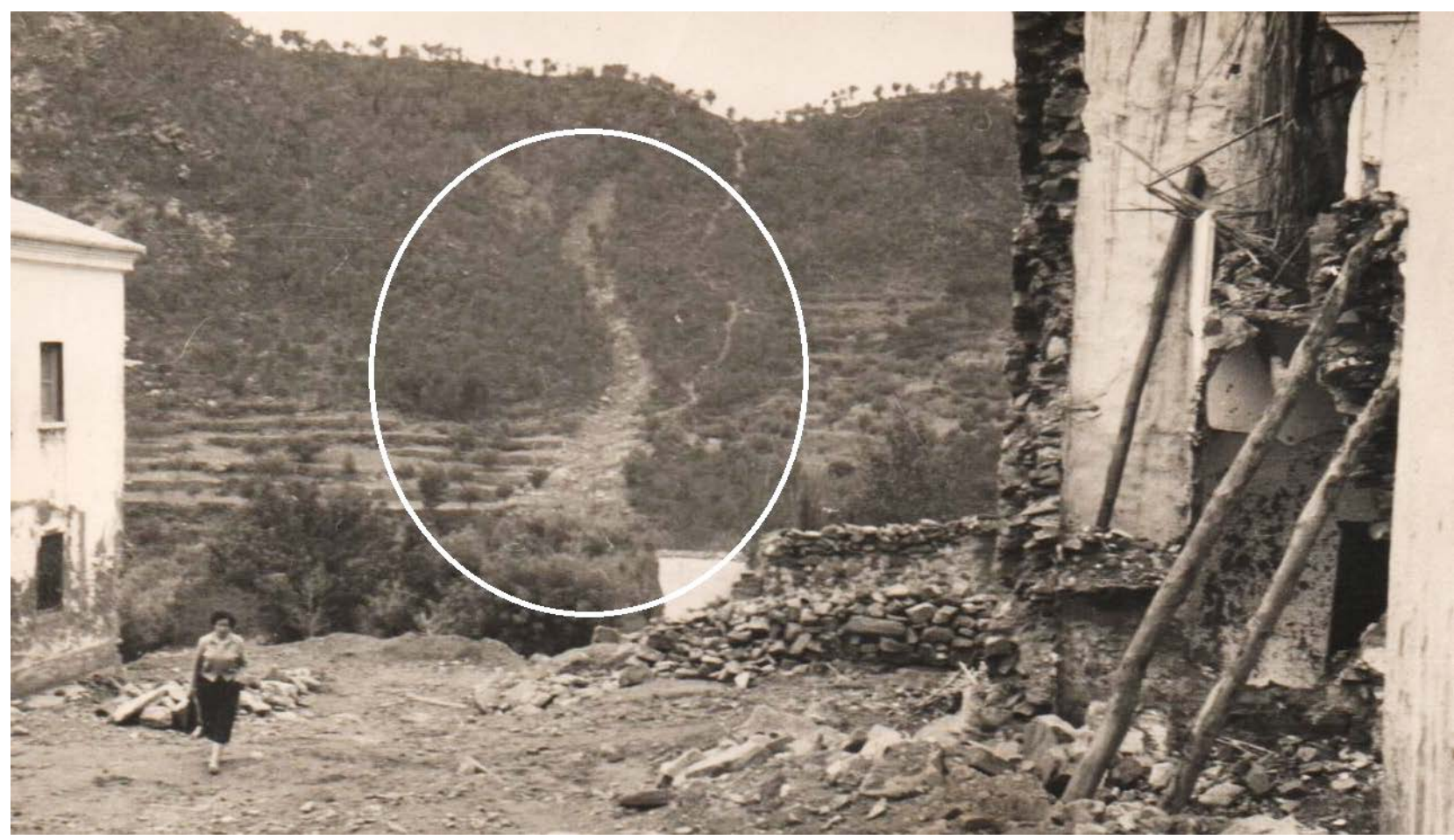

Nota: Fotografía [29 en Figura 2] desde el final de la calle del Vallejo. Este es el punto por donde buena parte del flujo del torrente salió a la CV-25 tras arrasar las tapias de varios corrales que se situaban entre las viviendas a izquierda (Casa del Médico) y derecha de la imagen.

Fuente: Julián Romero (1957) 
Figura 6. Localización de los depósitos de derrubios identificados en el entorno de Marines (círculos en amarillo) y perfil de uno de ellos (en naranja)
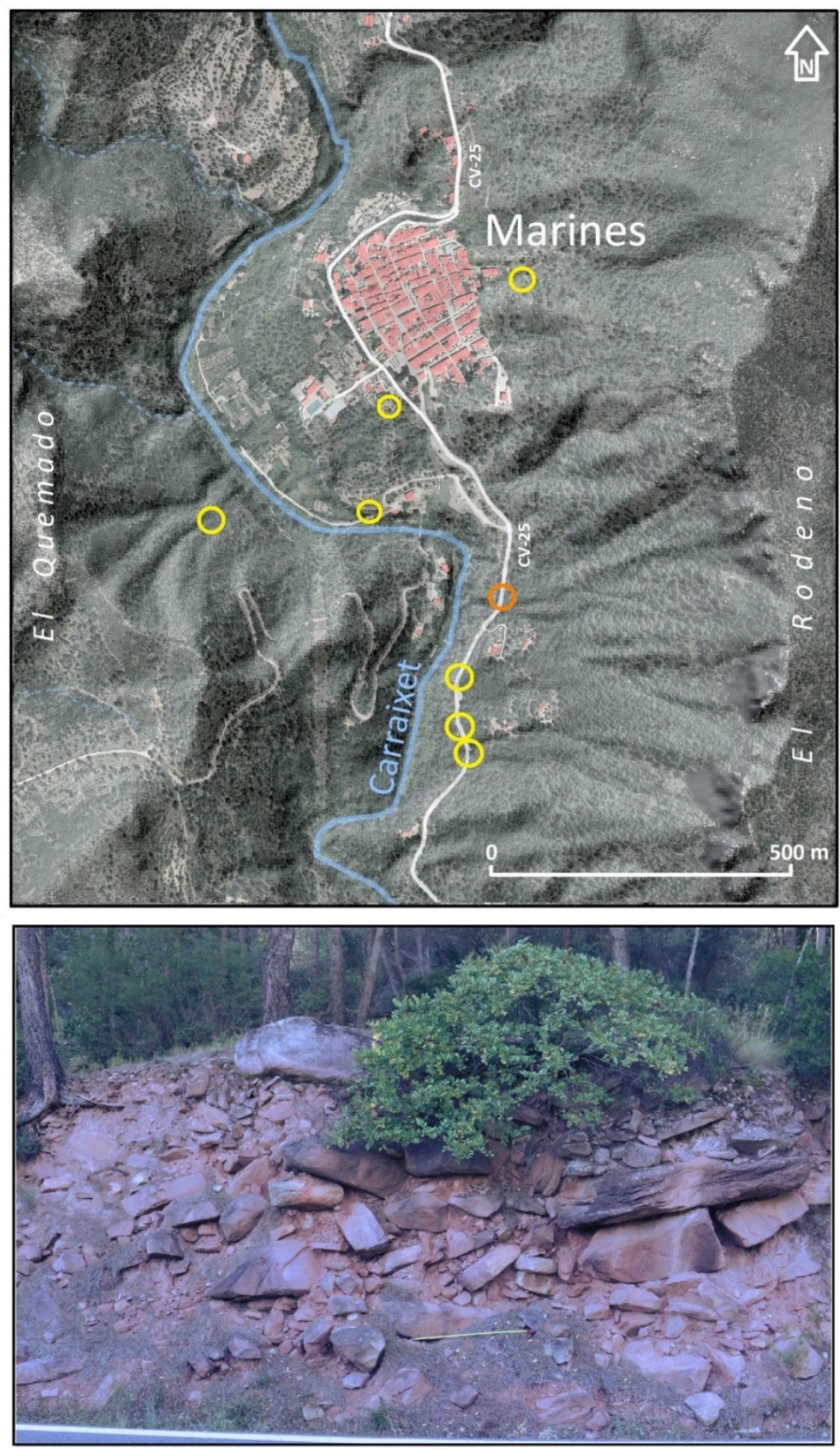

Nota: El flexómetro muestra $1 \mathrm{~m}$ de longitud

Fuente: elaboración propia a partir de la cartografía oficial de la Comunitat Valenciana a escala 1:5.000 en formato shape del Institut Cartogràfic Valencià, de la ortofoto de 2019 de la Comunitat Valenciana a escala 1:5.000 del Institut Cartogràfic Valencià, y del modelo de elevación del terreno de 5 metros de resolución de la Comunitat Valenciana del Institut Cartogràfic Valencià. Fotografía: Carles Sanchis Ibor 
Las fotografías posteriores al evento que asoló parte de Marines muestran tres fuentes de alimentación en la ladera del Rodeno. La de mayor tamaño procede de la base del Chimo, justo al pie de las cresterías de areniscas del Buntsandstein. Presenta una importante cicatriz longitudinal y se prolonga por un canal excavado sobre la ladera (Figura 7). Tras recorrer 250 $m$, este canal conecta con otros dos de menor tamaño que descienden desde el Escalón (Figura 8). Por el tamaño del escarpe, la sección del cauce abierto, y la localización del punto de arranque -en el contacto entre la cresta de areniscas y los materiales lutíticos-, la hipótesis más plausible es que el movimiento de masa se originara en este punto y que la remoción de materiales en la base de la ladera del Escalón facilitara la activación de procesos similares en los dos cauces menores de esta vertiente. No debe descartarse que esta remoción tenga origen en la formación de escorrentía superficial hortoniana.

Figuras 7 y 8 . A la izquierda, imagen tomada desde el pico del Chimo, que muestra la cicatriz de cabecera y el arranque del canal del flujo de derrubios
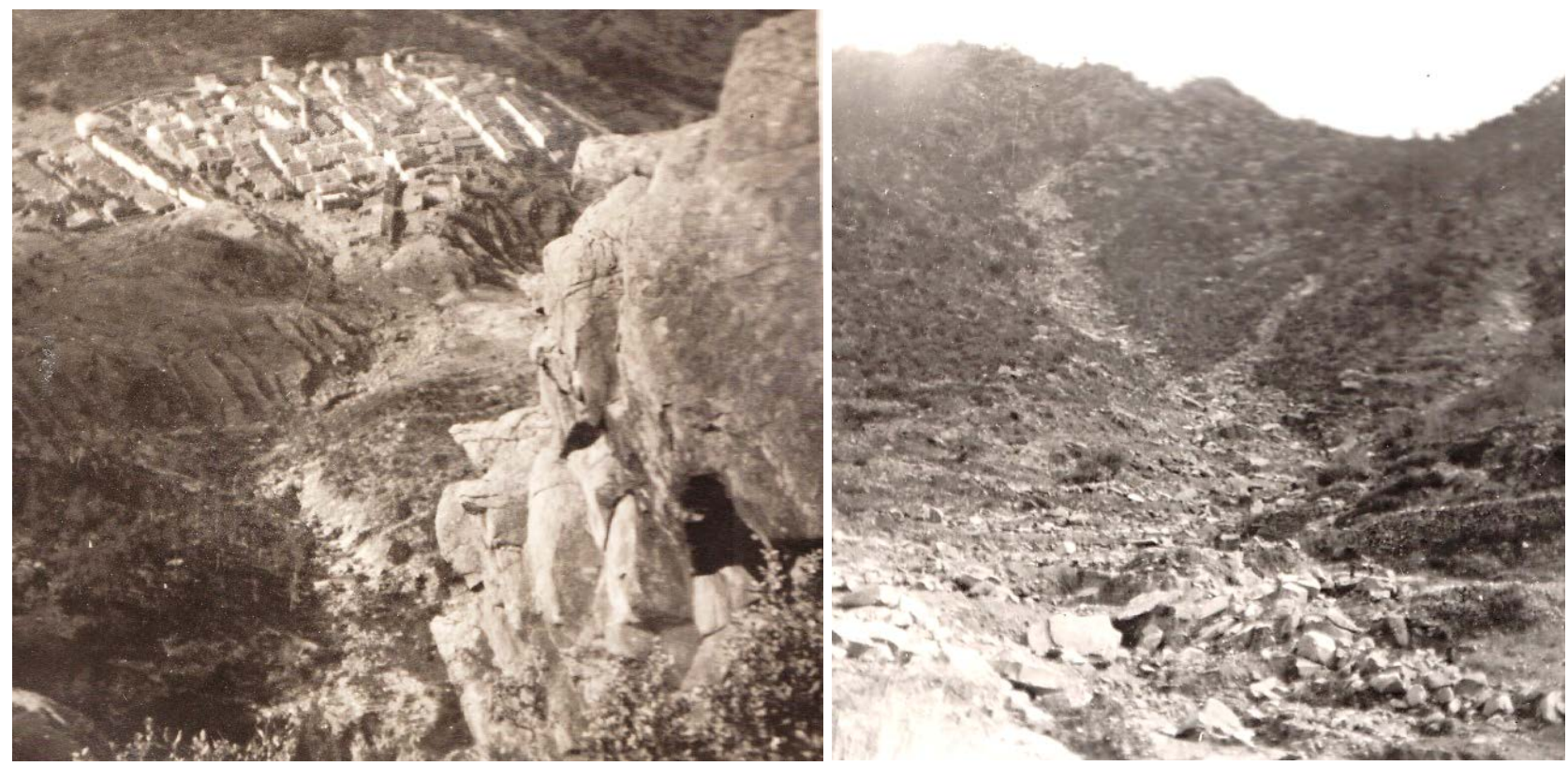

Nota: A la derecha [4 en Figura 2] se observa el canal poco antes de su llegada a Marines y los dos canales tributarios abiertos desde la ladera del pico del Escalón.

Fuente: Archivo Diocesano de Valencia (1957)

Entre la citada confluencia y las primeras casas del casco urbano la pendiente se reduce significativamente (pasa de un $50 \%$ a un $21 \%$ ). En este tramo, el trazado del cauce describe una leve curvatura forzado por un resalte del relieve, de areniscas blancas, que impide la conexión del Vallejo con la vaguada o barranco de Ñivera, el cual limita el casco urbano por el 
noroeste. Las fotografías reproducen un cauce abierto que, a partir de los restos de las edificaciones, hemos estimado en 16 metros de anchura media aproximada. En este se observan depósitos compuestos principalmente por bloques submétricos y algunos ejemplares de dimensiones métricas. Algunas imágenes muestran también un reguero encajado algo más de un metro sobre el nivel del suelo anterior al evento, coincidente con el tálveg actual del Vallejo (Figura 9). El tálveg queda a la margen izquierda del cauce y a su derecha dejó abundante material acumulado, que alcanzó la trasera de las viviendas de la calle Purísima (Figura 9). Todas las edificaciones que abrazan el cauce por ambas márgenes a su llegada al casco urbano sufrieron derrumbes parciales. No quedaron restos de vegetación y en las imágenes tan sólo se aprecia parte del tronco de algún árbol que ha perdido su corteza y ramaje.

La calle del Vallejo tenía una anchura de solo 2 metros en su inicio, se ampliaba a 3,5 metros más abajo, y tras el cruce con la calle Cristo alcanzaba poco más de 5 metros. La paralela calle de Vicente Coll, solo presentaba 3,5 metros de amplitud. En consecuencia, las edificaciones provocaban un estrechamiento demasiado exigente para el canal abierto por el flujo, que a la postre resultó dramático. La primera vivienda de la alineación situada entre ambas calles actuó como un tajamar, partiendo en dos el flujo y siendo destruida por completo ${ }^{3}$. La siguiente vivienda tampoco resistió el impacto de la carga sólida y se derrumbó, quedando solo en pie su pared mediera con la tercera vivienda y causando la muerte en el acto a 3 de sus 4 habitantes (Figura 10). ${ }^{4}$

3 En dicha vivienda fallecieron María del Carmen Calvet (5), María Sánchez Rozalén (62), Antonio Idrag Sánchez (30), mientras que José Idrag fue rescatado con heridas de gravedad: "en el corral estaba el tío José y asomaba solo la mano. La casa de enfrente era del tío Santiago y él se dio cuenta de que había un gato y era la mano para que le viesen, porque no podía gritar. Se llenó todos los conductos de barro. Entonces cuando se dieron cuenta lo sacaron y se lo llevaron. Como no había camillas ni nada se lo llevaron en un cañizo [...] por el Quemao, porque por la carretera no se podía pasar" (Entrevista 1).

4 En esta primera vivienda fallecieron Miguel Orero (69 años) y Cecilia Ecrig (67). 
Figura 9. Composición a partir de dos fotografías [8 y 10 en Figura 2] que muestra el tálveg del canal abierto por el flujo de derrubios en el Vallejo y la trasera de las viviendas de la calle Purísima.

A la izquierda, la primera vivienda de la calle Vicente Coll

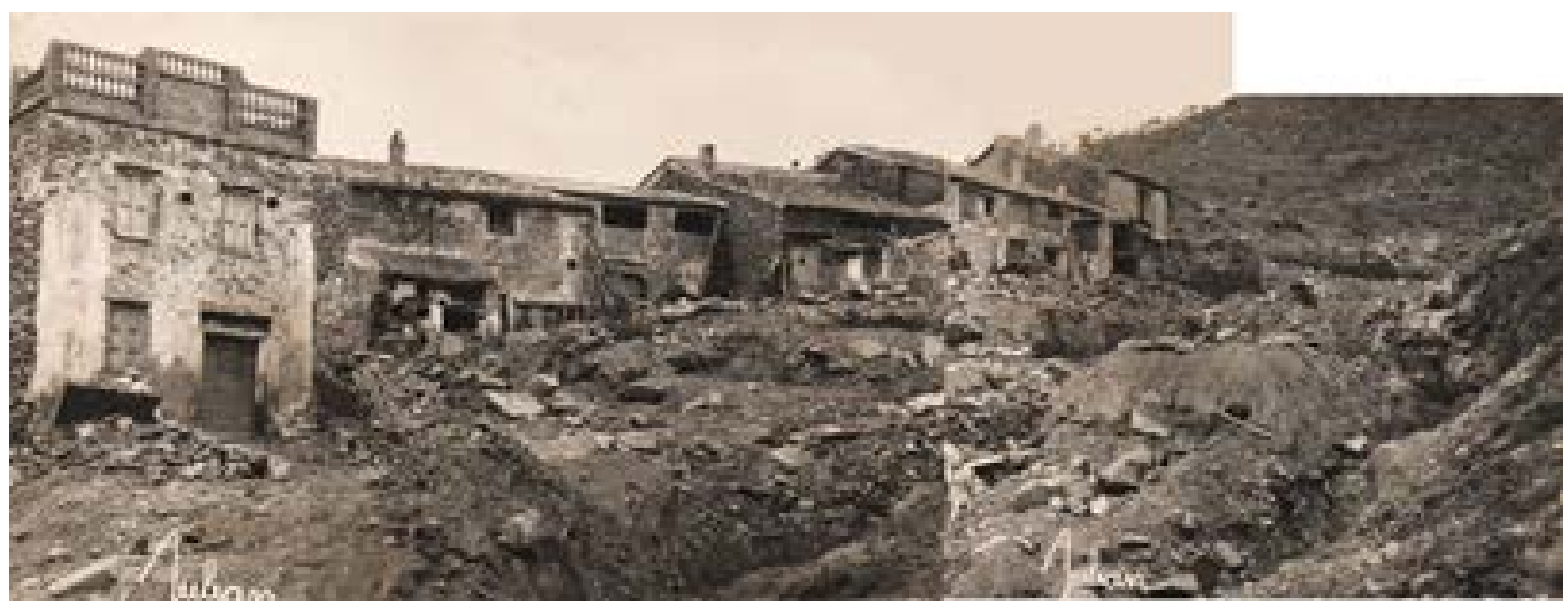

Fuente: composición a partir de las fotografías de Julián Romero (1957)

Figura 10. Composición a partir de dos fotografías [14 y 25 en Figura 2] que muestra la pared mediera de una de las dos viviendas derribadas por el flujo

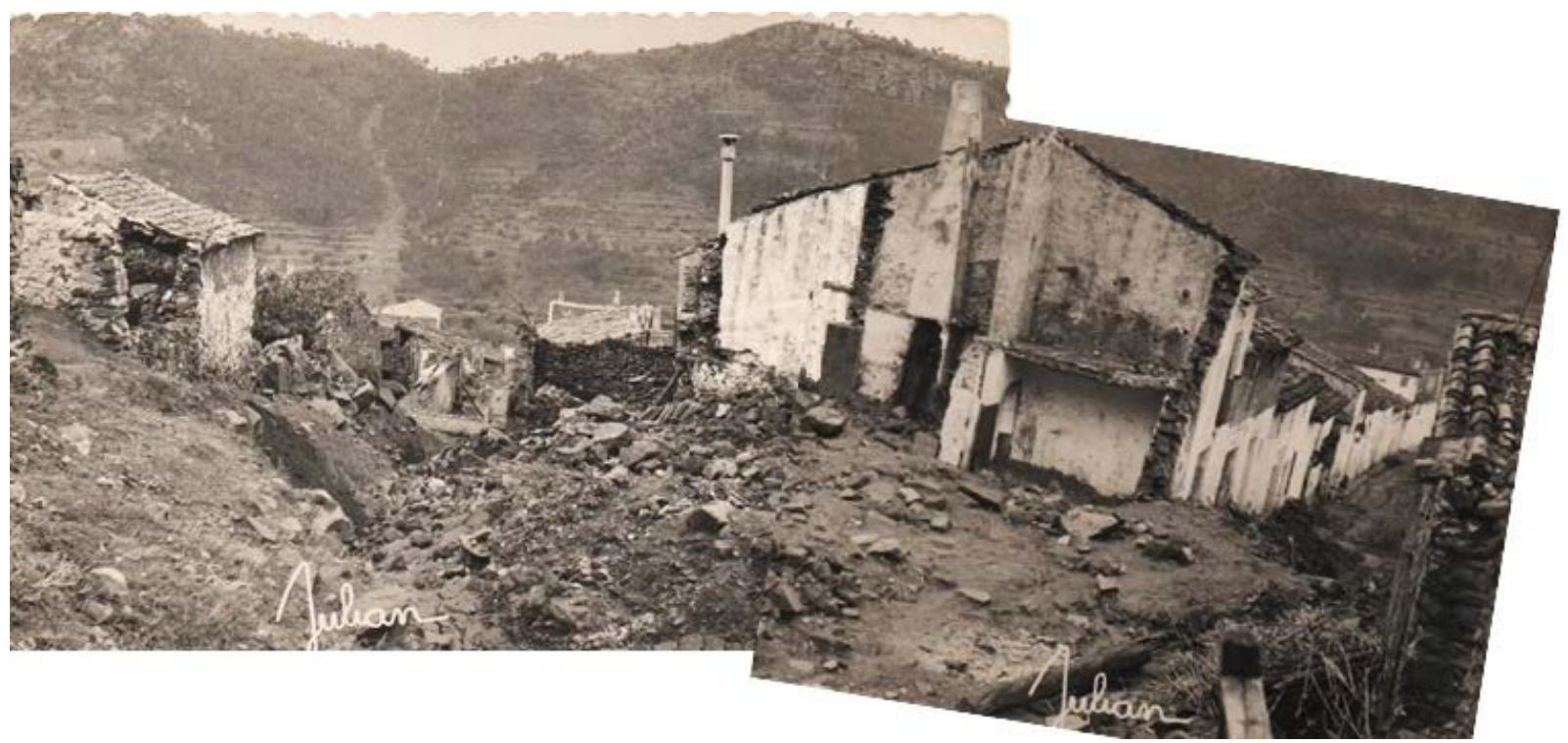

Nota: A la izquierda el tálveg del torrente discurre hacia la calle del Vallejo y a la derecha se observa la calle Vicente Coll, ya limpia de los derrubios que la bloquearon por completo.

Fuente: composición a partir de las fotografías de Julián Romero (1957)

La mayor parte del flujo discurrió por la calle del Vallejo o las Delicias. En el sector más estrecho, el más alto, derribó parcialmente muros y dejó un surco aparentemente superior a un 
metro por debajo de la cimentación de las estructuras (Figura 11). A la salida de este estrechamiento el impacto sobre las construcciones fue mayor, probablemente como resultado de un efecto Venturi. Todos los corrales fueron arrasados y los muros de las viviendas reventaron. En la primera de ellas es donde halló la muerte el vecino José María Cortell ${ }^{5}$. Sin embargo, en el tramo inmediatamente inferior, pasado el punto donde la calle se amplía, los daños sobre las viviendas aunque importantes, fueron menores. El pavimento de adoquines de rodeno resistió el paso del flujo y no se produjo ninguna marca de incisión significativa sobre este lecho artificial (Figura 12). En este tramo, las marcas dejadas por el barro en las paredes de algunos edificios que no cedieron al empuje y que conservan todavía hoy la misma estructura de vanos nos permiten conocer la altura alcanzada por el flujo, que oscila entre los 2,40 y los 1,50 metros en distintos puntos de dicha calle. Cuando el flujo se detuvo, el sedimento que quedó en la calle, principalmente de granulometrías finas, alcanzaba una altura aproximada de $50 \mathrm{~cm} .^{6}$

\section{Figuras 11 y 12. Fotografías tomadas prácticamente en el mismo punto (izquierda, aguas arriba) (derecha, aguas abajo), donde la calle del Vallejo cruza la calle Cristo y se ensancha}
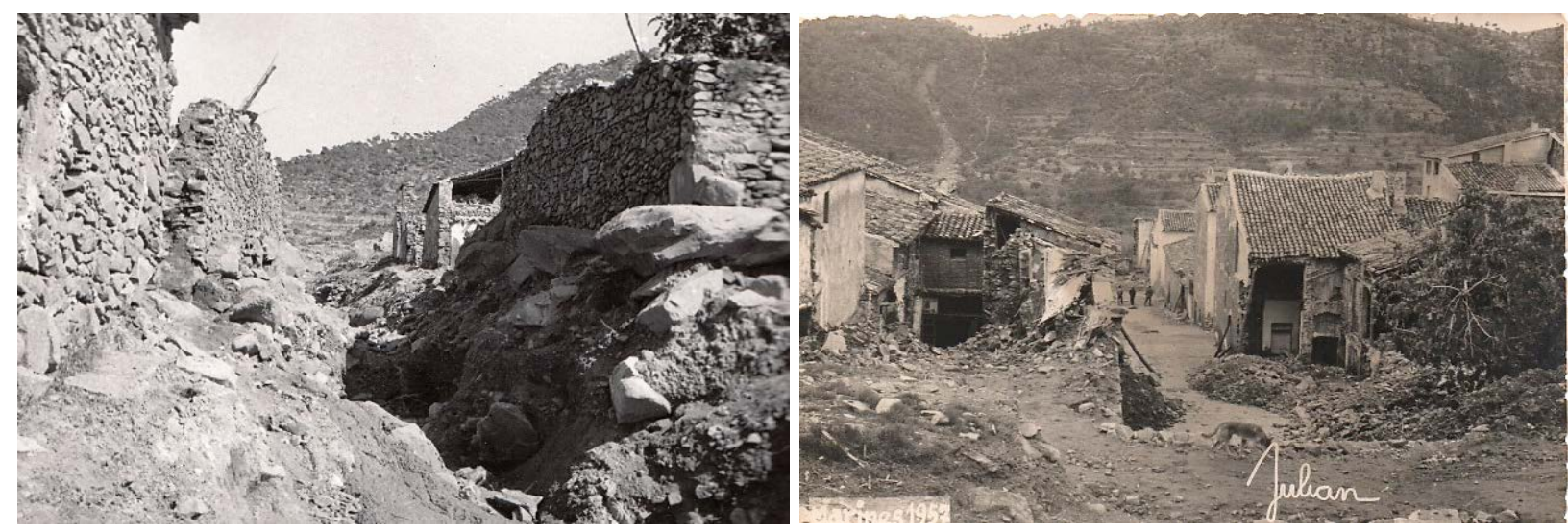

Nota: Las ruinas a la derecha de la segunda imagen corresponden a la vivienda donde falleció José María Cortell.

Fuente: Archivo Diocesano de Valencia (1957) (izquierda); Julián Romero (1957) (derecha)

En paralelo, a tenor de los efectos, el flujo discurrió con menos energía por la calle Vicente Coll. Pese a ello, pudo desplazar un bloque de grandes dimensiones que quedó atascado a media

5 José María Cortell, según el testimonio de su esposa, había bajado desde su vivienda hasta el corral adjunto, donde tenía su mulo, para apuntalar el portón y defenderlo de los embates de las aguas turbias del Vallejo. Su hijo trató de disuadirlo, pero mientras maniobraba en el portal fue sorprendido por el flujo de derrubios que destruyó todos los corrales de su calle y parte de las viviendas (Entrevista 1)

6 Rafael Deltoro (2002) describe que atravesó el Vallejo subido a la espalda de su padre, a quien el barro que había quedado en la calle le llegaba hasta las rodillas. 
pendiente, antes de la intersección de la calle Cristo. Este bloque impidió el paso de los demás sedimentos, que en dicho punto arrastraban maderas, cañizos y mampuestos de los derrumbes producidos aguas arriba (Figura 13). La acumulación de los sedimentos retenidos por este bloque, y la presión ejercida por el flujo, reventaron los muros de algunos edificios situados en la margen izquierda del sentido de la corriente. En otras casas el sedimento entró por puertas y ventanas cegando toda la planta baja. No obstante, la roca retuvo el sedimento grueso y evitó daños significativos en las viviendas y el adoquinado dispuestos aguas abajo. Este hecho facilitó el rescate rápido de las personas atrapadas en las viviendas, gracias a que los familiares y vecinos pudieron acceder a socorrerles, a través de balcones y tejados. ${ }^{7}$

El flujo que había descendido principalmente por la calle del Vallejo llegó posteriormente a la Plaza del Sol donde causó graves daños a la primera vivienda y desplazó de su sitio, sin derribarla, la Casa del Médico, que había sido construida tres años antes, en 1954. Entre ambas existían unos corrales que fueron completamente arrasados. Por ellos atravesó la mayor parte del flujo, que saltó a la carretera, la cruzó y entró en los olivares aterrazados. Toda la plaza, la carretera y los huertos quedaron cubiertos por materiales muy heterogéneos. En las fotografías recopiladas y sobre el terreno hoy cultivado se observan arcillas, cantos angulosos, bloques decimétricos y algunos de dimensiones superiores a un metro (Figuras 13, 14 y 15).

7 La entrevistada n 1 narra este suceso: "Luego cayó una piedra que taponó una calle. [...] Mira si era grande entonces todo lo que iba bajando de la montaña se cobijaba allí en la piedra. ¿Qué pasó? Que al estar todo el barro ahí más los pinos, piedras.... Las casas que habían en el lado izquierdo reventaron y tuvieron que sacar a la gente por arriba por los balcones y darse prisa [...] tuvieron que poner una escalera, que en eso fue mi padre que sacó a su hermano, y sacó a la familia [...] y el caballo se le quedó enterrado que le llegaba el barro por la cabeza y no lo pudieron sacar en ese momento. Aquello daba miedo, de verdad". Deltoro (2002) relata como al cesar el flujo, la familia residente en una de las casas donde se formó este dique, habiendo quedado cegada su planta baja, salió por su propio pie a la calle por el balcón, acompañados por el burro que poseían. 
Figura 13. Imagen tomada que muestra la calle Vicente Coll obstruida por los derrubios

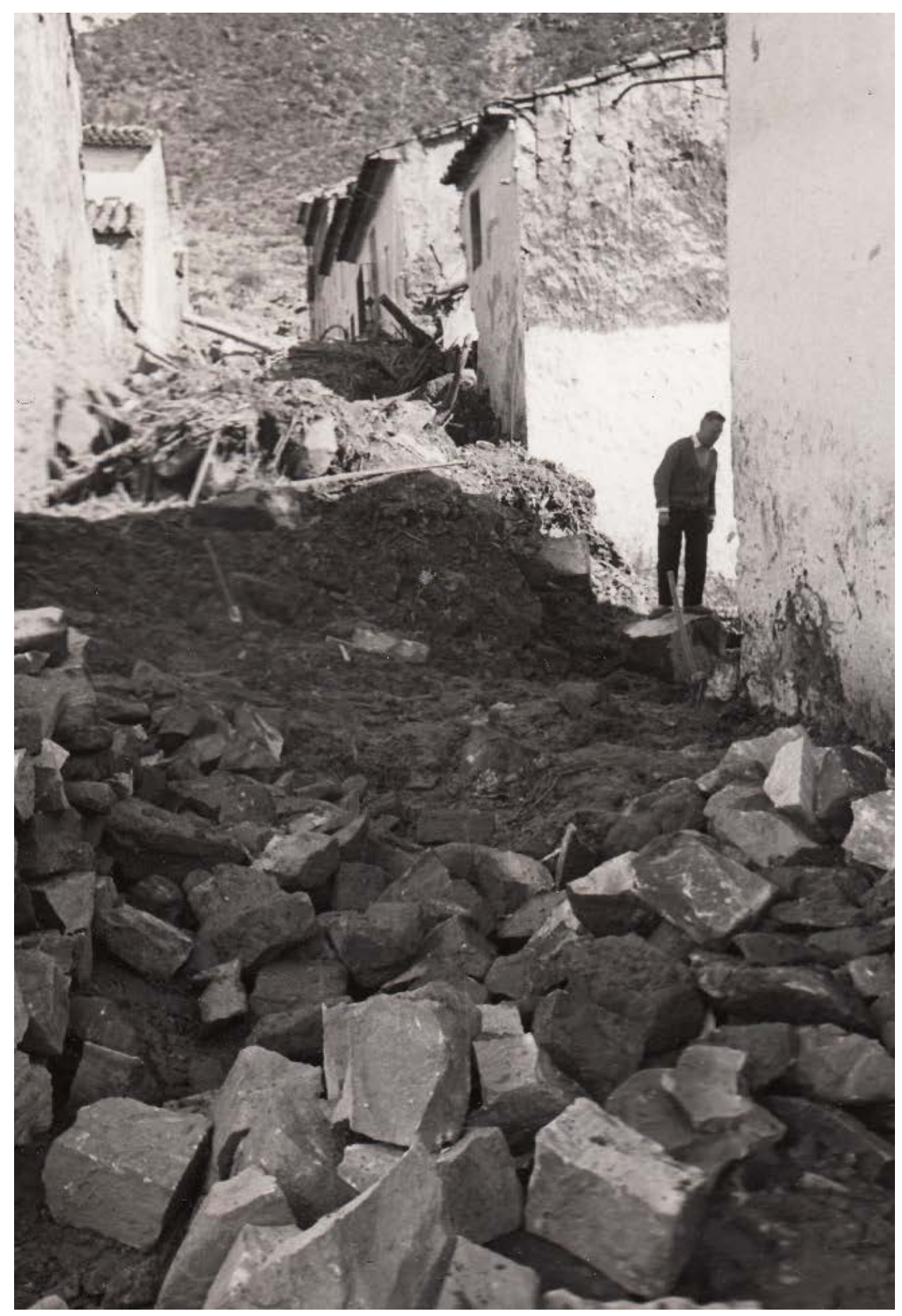

Nota: El informe del arquitecto Cayetano Borso di Carminati (ADV, 1957) detalla como la piedra que frenó el flujo fue troceada por los canteros para su traslado, tal y como muestra la parte inferior de la imagen.

Fuente: Luis Vidal (1957)

En la Plaza del Sol la pendiente se reduce sensiblemente (se halla en torno al 13 \%), hecho que, unido a la liberación del confinamiento generado por el callejero, permitió la dispersión y 
deposición de los sedimentos. La crónica de Deltoro (2002), que contaba con 9 años en aquel momento, atribuye buena parte de los daños causados por el flujo en la calle del Vallejo a un bloque de grandes dimensiones que finalmente quedó frenado en la Plaza del Sol, junto a la Casa del Médico. En la Figura 14 se observa parte de los restos de este bloque, que tardó varios días en ser triturado por los canteros. Junto a parte de sus restos aparecen otros bloques de dimensiones decimétricas y abundante sedimento areno-arcilloso procedente de la ladera, frente a una menor presencia de granulometrías medias.

El lóbulo final del flujo arranca de la misma plaza y parece presentar dos lenguas, una primera que prolonga la dirección E-O del trazado de la calle del Vallejo, y otra que giró siguiendo el curso natural de la vaguada del Vallejo. No existen fotografías suficientemente cercanas de estos depósitos. Con posterioridad, los bancales afectados fueron reconstruidos y buena parte de esta zona ha sido urbanizada. No obstante, en algunas de las parcelas y en alguna senda quedan restos de estos depósitos, y también se reconoce algún bancal reconstruido con un margen de piedra seca que denota menos pericia constructiva que otros del paraje y evidencia el aprovechamiento los derrubios acumulados en la zona.

Aguas abajo de este depósito, se han documentado varios acarcavamientos generados por flujos de menor densidad, que debieron arrastrar materiales más finos hacia el barranco (Figura 15). A cotas más próximas al barranco, sobre el perfil del camino del Collado, hemos reconocido un estrato reciente de materiales de granulometrías medias y finas que podría asociarse a este episodio. Este cubre un suelo agrícola anterior con textura de cantos angulosos heterométricos sobre matriz fina (Figura 16) y se sitúa muy próximo a otros depósitos de flujos de derrubios de mayor antigüedad.

El proceso de análisis de la información recopilada nos ha permitido precisar la veracidad de algunos documentos oficiales que trataron de sobredimensionar los daños causados por el evento -ya de por si suficientemente grave y doloso-, con la evidente finalidad de recibir el auxilio de las administraciones públicas. En este sentido, el informe elaborado por orden de la alcaldía incluía la Casa Consistorial y la Iglesia del Cristo del Perdón entre las construcciones damnificadas, pese a que ambas quedaron a salvo del flujo de derrubios (aunque no de las lluvias torrenciales). El número de edificios afectados también fue exagerado por la prensa. Las Provincias (1957a) y Levante (1957a) mencionan 28 casas completamente destruidas y 132 gravemente dañadas, mientras que los informes oficiales (Cortell, 1957) redondean a 100 (10 destruidas, 30 inhabitables y 60 afectadas), cifra algo más próxima a la realidad. Este análisis 
también nos ha permitido desvincular el flujo de derrubios de un depósito de grandes dimensiones (Figura 17) situado entre el Puente del Collado y la CV-25, el cual aparece bien documentado por la colección fotográfica. Este presenta un predominio casi absoluto de materiales gruesos, que fueron triturados y reaprovechados por los canteros del pueblo. Por su emplazamiento y posición topográfica, de imposible conectividad hidráulica con el flujo de derrubios, debemos desvincularlo de este evento. Su origen parece mixto. Está vinculado a las tareas de desescombro de las calles y edificios de Marines - de hecho se convirtió en un vertedero incontrolado hasta su clausura a inicios del presente siglo-, pero allí también se acumularon otros materiales procedentes de los torrentes que bajan del Escalón, en los que se produjo un importante acarcavamiento durante el temporal de lluvias.

\section{Figuras 14 y 15. A la izquierda (ADV) acumulación de derrubios frente a la Casa del Médico}
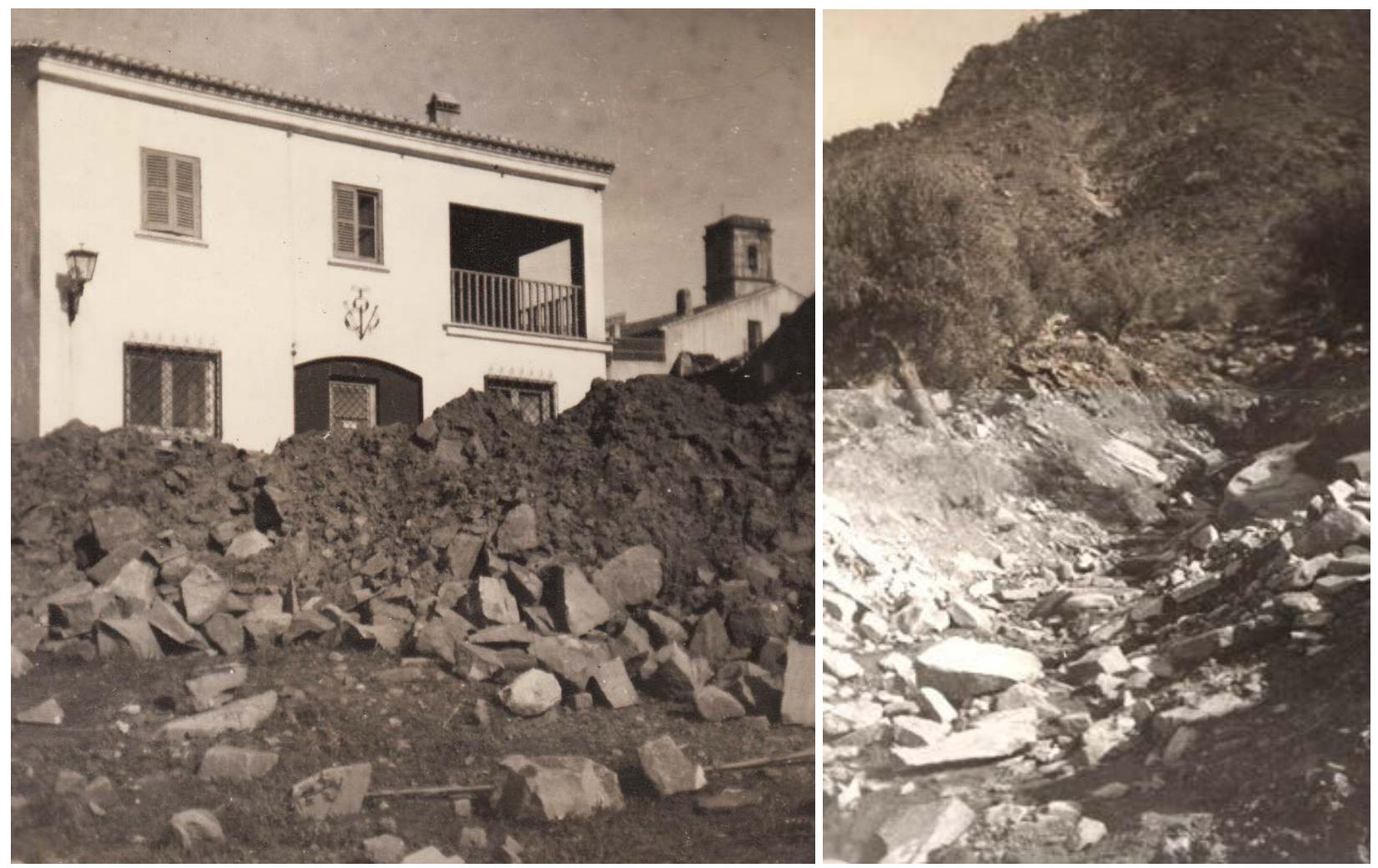

Nota: A la derecha composición a partir de dos fotografías del ADV que muestra el acarcavamiento generado por el flujo aguas abajo del lóbulo principal compuesto por materiales gruesos.

Fuente: Archivo Diocesano de Valencia (1957) 
Figura 16. En el camino del Collado, en la parte superior del perfil se observa un estrato de $20 \mathrm{~cm}$ de espesor formado por cantos angulosos que no hemos podido datar, pero que se superpone al perfil de un suelo agrícola desarrollado sobre depósitos de ladera. Por su localización, aguas abajo del lóbulo del evento de 1957 y al final de una de las cárcavas activas, la hemos atribuido a este episodio

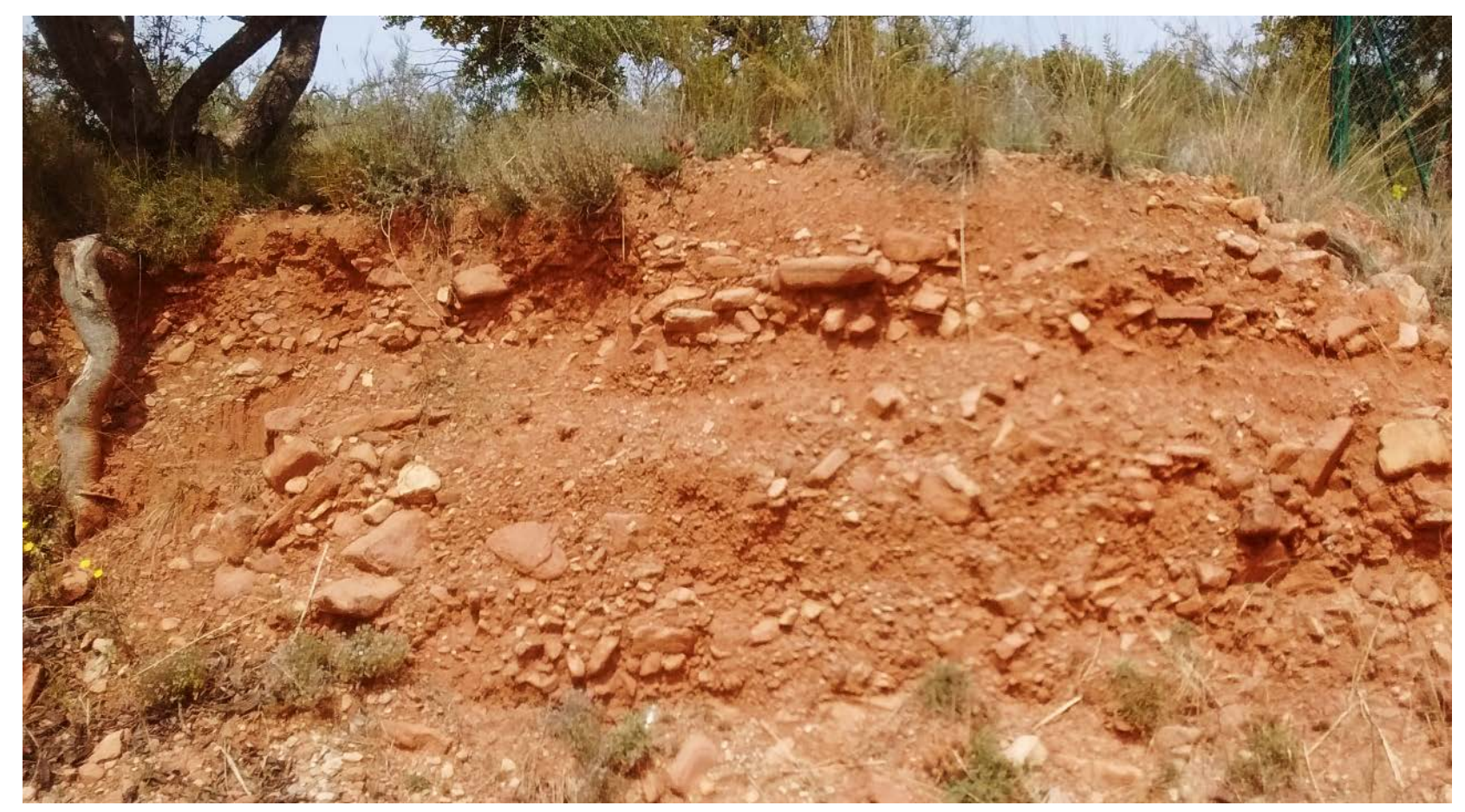

Fuente: elaboración propia (2019) 
Figura 17. Composición efectuada a partir de dos fotografías de autor anónimo incluidas en el informe de la alcaldía depositado en el ADV (1957)

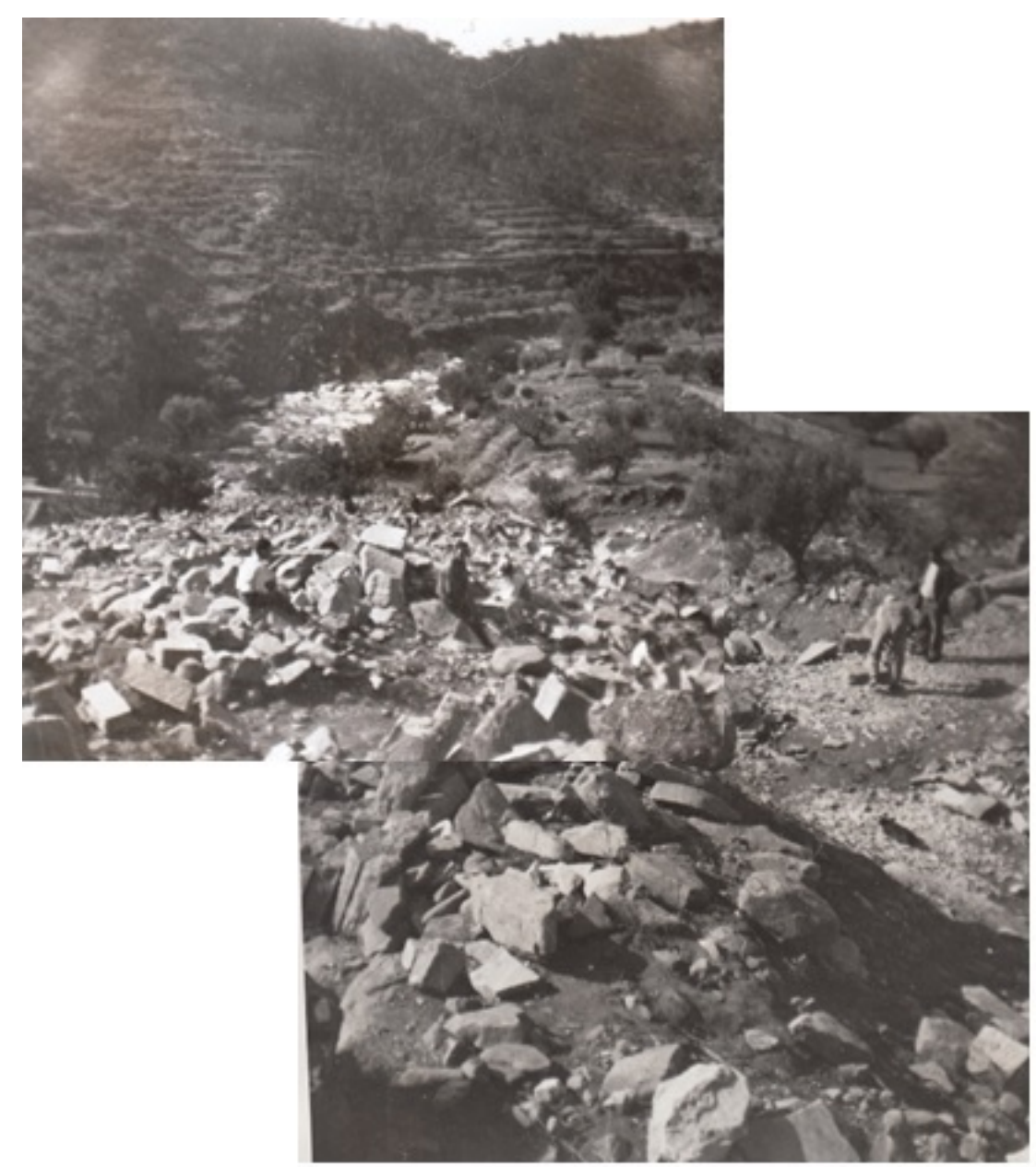

Nota: Se observa la escombrera generada por el traslado de los derrubios acumulados en Marines y algunos aportes de los torrentes del Escalón.

Fuente: Archivo Diocesano de Valencia (1957) 
Figura 18. Ortofotomapa de formas asociadas al evento y afección sobre construcciones, realizado a partir de la fotografía aérea del "vuelo americano" de 1957

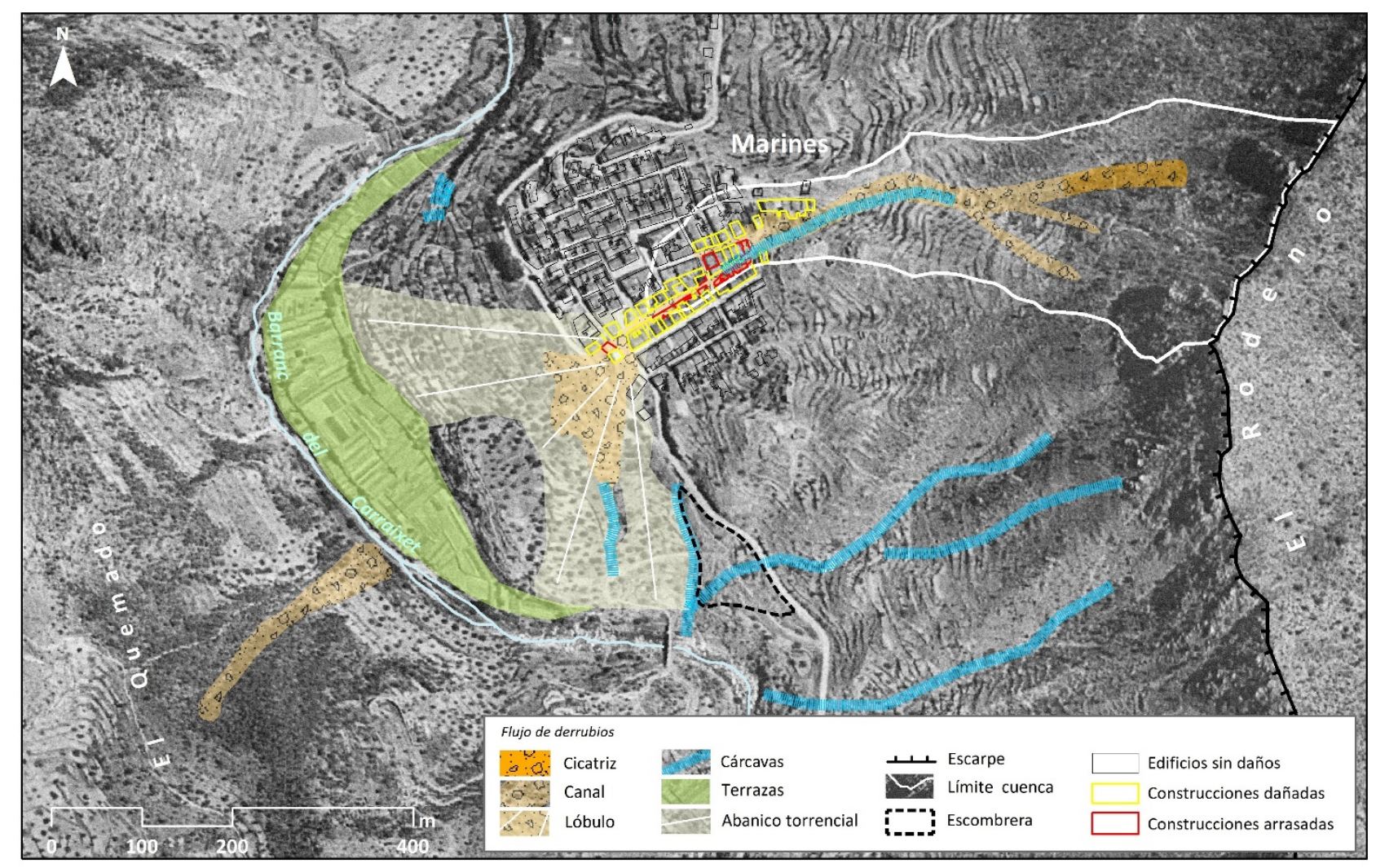

Fuente: laboración propia sobre fotografía aérea del Servicio Geográfico del Ejército (1956)

\section{Discusión, conclusiones y una reflexión a modo de epílogo}

El movimiento de masa que arrasó parte de las viviendas de Marines el 14 de octubre de 1957 presenta buena parte de las características que definen un flujo de derrubios o debris flow. El volumen y la textura de la carga sedimentaria se corresponde con el propio de estos fenómenos, según se desprende las fotografías, los informes y los testigos consultados. Además, por un lado, las condiciones de la cuenca, de reducido tamaño y poca capacidad de generación de caudal, hacen difícil la generación de un flujo hiperconcentrado de las dimensiones del que atravesó Marines. Por otro, la existencia de un canal que confinó e hizo circular el flujo describiendo una doble curva hasta Marines, lo separan de los movimientos categorizados como avalanchas de derrubios (Hungr et al., 2001).

No obstante, debe reconocerse la naturaleza transitoria y cambiante de estos fenómenos, como han señalado Hungr et al. (2001) y Takahashi (2001). En el transcurso de cada evento suelen darse fases de diferentes condiciones reológicas, que en algunos momentos pueden estar más próximas a las avenidas de derrubios (debris flood) o a coladas de fango (mud flow) y en otros 
asemejarse a las avalanchas de derrubios (debris avalanche). En este suceso, las descripciones de los testigos y las marcas de barro en algunas paredes denotan un flujo inicial de baja densidad, previo a la movilización de derrubios. Cabe pensar en un flujo inicial acuoso, tipo colada de fango, que precedió al flujo de derrubios y que fue el que primero alertó a algunos vecinos.

Se produjo, en definitiva, un proceso mixto, un deslizamiento en cabecera que se transformó en un flujo de derrubios, y que probablemente circuló con un flujo de fango en la parte frontal (Takahashi, 2001). Estos movimientos son relativamente frecuentes en contextos litológicos como el del Rodeno, donde existe una base de materiales plásticos (formación Marines, Garay-Martín, 2005) sobre la cual se apoya un roquedo más compacto (formación Garbí, Garay-Martín, 2005). Son fenómenos transitorios y también espacialmente heterogéneos, puesto que, si bien en el área identificada como canal del flujo existía un cauce previo, la cicatriz se sitúa en una zona no confinada, por lo que allí el movimiento pudo reunir condiciones más propias de una avalancha de derrubios formada principalmente por las areniscas de la crestería (Hungr et al., 2001).

La categorización del movimiento de masa es más dificultosa en el suceso del Quemado, ya que solo disponemos de fotografías lejanas y no hay referencias documentales ni de testigos. En este caso el confinamiento del canal es prácticamente inexistente y resulta difícil adscribir el fenómeno como flujo o avalancha de derrubios. Este hecho pone de relieve el valor de la clarificadora aportación tipológica de Hungr et al. (2001), y su consideración de clasificación no taxonómica. La naturaleza siempre deja zonas grises entre algunas categorías vecinas, bien por la dificultad de establecer criterios cuantitativos entre algunas de ellas o bien por la imposibilidad de estimar estos parámetros con posterioridad al episodio en zonas donde no existen sistemas de monitorización o los depósitos han sido muy modificados o desaparecido con el paso del tiempo.

El flujo de derrubios que asoló Marines y el flujo o avalancha que hemos documentado en el monte del Quemado se produjeron en un contexto de precipitaciones intensas y afectaron a laderas con pendientes máximas superiores al 50 \% y litologías caracterizadas por la presencia de estratos de dureza desigual de facies Buntsandstein. La presencia de depósitos similares en otras laderas próximas exige un trabajo más amplio y sistemático para contrastar, como se ha efectuado con la facies Flysch en los Pirineos (Martínez-Castroviejo y García-Ruiz, 1990; Lorente et al. 2002), si las zonas de roquedo de facies Buntsandstein del sector oriental de la Cordillera 
Ibérica muestran una mayor susceptibilidad a estos fenómenos que otras litologías presentes en estas montañas.

Por otra parte, la comparación de ambos eventos, en vertientes opuestas entre sí y con condiciones muy similares, pone de relieve la limitada capacidad de la vegetación para atenuar estos fenómenos. La avalancha o flujo de derrubios del Quemado tuvo lugar, a diferencia de lo sucedido en Marines, en una vertiente casi completamente cubierta pinos y arbustos. Una densa cubierta vegetal, si bien indudablemente puede reducir la peligrosidad (Lasanta et al., 2006, Beguería et al., 2006), no inhibe el desarrollo de estos fenómenos, algo que es importante remarcar para evitar transmitir una sensación de falsa seguridad que facilite actividades o instalaciones antrópicas en zonas de elevada potencialidad para el desarrollo de estos movimientos súbitos.

Este trabajo de reconstrucción ha permitido reconocer tanto los procesos, como las formas propias de estos eventos, y hemos podido documentar la posición y dimensiones aproximadas de la cicatriz inicial, el canal y el lóbulo final. A pesar de la distorsión que introduce el área urbana atravesada por el flujo, el punto en el que arranca el lóbulo central se corresponde perfectamente con el cambio de pendiente que marca el arranque de la zona apical del abanico torrencial. Asimismo, aunque es aventurado proponerlo sin un estudio hidráulico, los daños sobre las viviendas parecen guardar coherencia con los cambios en la sección del canal. Los puntos en los que se produjo una divergencia del flujo por un obstáculo o por la liberación de un relativo confinamiento son donde se registraron los mayores daños sobre las infraestructuras urbanas y por desgracia también, sobre las víctimas.

La reconstrucción de la disposición de las fotografías y la delimitación del lóbulo final no han estado exentos de dificultades. Estas tareas, y en particular la desvinculación del depósito o escombrera situado al sur del casco urbano (Figura 17) del flujo de derrubios del Vallejo, pone de relieve la conveniencia de utilizar y contrastar fuentes variadas (orales, documentales, fotográficas y geomorfológicas) para la reconstrucción de estos eventos históricos, contribuyendo de esta manera a recomponer fenómenos cuya información tiende a desvanecerse o deteriorarse con el paso del tiempo.

¿Qué ha sucedido en Marines con posterioridad a esta tragedia? En su informe adjunto a la documentación municipal (ADV, 1957), el arquitecto Cayetano Borso di Carminati apuntaba que "evitar la repetición de estos accidentes debería ser objeto de un detenido estudio a base de una completa repoblación forestal de la ladera o construcción de unos potentes muros de 
abancalamiento que impidieran la formación de aludes, soluciones a muy largo plazo la primera y de elevadísimo coste la segunda, sin que en ningún caso se pudiera asegurar de manera absoluta que la formación de aludes sería cosa imposible". Los sucesos posteriores han materializado las propuestas del arquitecto racionalista. Si bien no se ejecutó ninguna costosísima operación, sí que se construyeron 12 modestas trampas de sedimento de mampostería sobre el cauce del Vallejo, inmediatamente aguas arriba de la población, que hoy ya están colmatadas. Una de ellas fue posteriormente recrecida con dos hileras de ladrillo de cemento para desviar las aguas hacia el barranco de Nivera por un pequeño canal. Por otra parte, la vegetación colonizó la ladera y los antiguos bancales están ahora ocultos entre el arbolado y el denso estrato arbustivo.

Estas transformaciones dan una falsa impresión de seguridad a los habitantes que han repoblado Marines. Tras el traslado de la población al llano de la Maimona, algunos propietarios mantuvieron sus casas y otros las han vendido a veraneantes, dando lugar a una colonia estival que ronda el millar de personas pero solo mantiene 65 habitantes censados durante el invierno. Casi todas las casas asoladas se han reconstruido. El peligro se ha atenuado por la presencia de la vegetación y el modesto efecto de las trampas de sedimentos, pero subsiste un riesgo evidente. Es bastante cuestionable la conveniencia de repoblar el área del casco urbano afectada por aquel evento y abandonada tras la construcción del nuevo asentamiento. Más aún por la forma en la que se han ejecutado estas operaciones. La renuncia al uso de instrumentos de ordenación urbanística se hace evidente en el diseño de la calle del Vallejo, que se reconstruyó recuperando las estrechas secciones anteriores, sin renunciar a un solo metro cuadrado de edificabilidad.

El flujo de derrubios que en 1957 aconteció en la ladera del Quemado, en una ladera boscosa y con unos pocos y bien cuidados bancales, es una buena prueba de la extensión de la peligrosidad por flujos de derrubios de las laderas del Rodeno, que presenta hoy día similares condiciones litológicas, topográficas y biogeográficas, y por tanto, el mismo potencial de respuesta ante fenómenos de precipitaciones de elevada intensidad. Estas circunstancias son particularmente preocupantes ante los registros máximos de precipitación observados en los últimos años (González-Herrero, 2018) y las estimaciones de incremento de la torrencialidad de las precipitaciones en la cuenca mediterránea asociado al calentamiento global (Alpert et al., 2002; Sánchez et al., 2004). 
Agradecimientos: El presente trabajo ha sido financiado por el proyecto CGL2017-86839-C3-1$\mathrm{R}$ del MINECO con fondos FEDER. Los autores agradecen las amables sugerencias de los dos revisores del documento y de los investigadores Gerardo Benito y Mikel Calle.

Declaración responsable: Las/os autoras/es declaran que no existe ningún conflicto de interés con relación a la publicación de este artículo. Las tareas se han distribuido de la siguiente manera: el artículo ha sido coordinado por Carles Sanchis Ibor, quien ha participado en la revisión bibliográfica, la recolección de datos, su análisis y la redacción del texto. Joan F. Mateu Bellés y Almudena Rozalén García han participado en la recopilación de datos y en la revisión del análisis y los textos elaborados por el primer autor. 


\section{Bibliografía}

ADV (1957). Escrito sobre la riada 1957 [Marines] y sus efectos con fotografías, Archivo Diocesano de Valencia, Año 1957, signaturas 27/5-4 y 621/5-4.

Alpert, P., Ben-Gai, T., Baharad, A., Benjamini, Y., Yekutieli, D., Colacino, M.M., ... Manes, A. (2002). The paradoxical increase of Mediterranean extreme daily rainfall in spite of decrease in total values. Geophys Research Letters, 29, 31.1-31.4. https://doi.org/10.1029/2001GL013554 Arattano, M., \& Marchi, L. (2008). Systems and sensors for debris flow monitoring and warning. Sensors, 8(4): 2436-2456. https://doi.org/10.3390/s8042436

Beguería, S. (2006). Changes in land cover and shallow landslide activity: A case study in the Spanish Pyrenees.

Geomorphology, 74 , $196-$

206. https://doi.org/10.1016/i.geomorph.2005.07.018

Benito, G., Grodek, T., \& Enzel, Y. (1998). The geomorphic and hydrologic impacts of the catastrophic failure of flood-control-dams during the 1996 Biescas flood (Central Pyrenees, Spain). Zeitschriff für Geomorphologie, 42, 417-437.

Berti, M., Genevois, R., Simoni, A., \& Tecca, P. R. (1999). Field observations of a debris flow event in the Dolomites. Geomorphology, 29(3-4), 265-274.

Bradley, J. B., \& McCutcheon, S. C. (1985). The effects of high sediment concentration on transport processes and flow phenomena. In International Symposium Erosion, Debris Flow and Disaster Prevention (pp. 219-225). Tsukuba, Japan,

Calvo, A. (1987). Geomorfología de laderas en el País Valenciano. València: Inst. Alfons el Magnànim.

Camarasa Belmonte, A. (1992). Génesis de crecidas en pequenas cuencas semiaridas: Barranc de Carraixet y Rambla de Poyo. Valencia: Confederación Hidrográfica del Júcar, Ministerio de Obras Públicas, Transportes y Medio Ambiente.

Camarasa-Belmonte, A.M., \& Segura-Beltrán, F., 2001. Flood events in Mediterranean ephemeral streams (ramblas) in Valencia region, Spain. Catena, 45(3), 229-249.

Cánovas, M. (1958). Avenidas motivadas por las lluvias extraordinarias de los días 13 y 14 de octubre de 1957. Revista de Obras Públicas, 106, I(2914), 59-68.

Carmona, P. (1997). La dinámica fluvial del Turia en la construcción de la ciudad de Valencia. Documents d'Anàlisi Geogràfica, 37, 85-102 
Carrasco, R.M., Pedraza, J., Martín-Duque, J.F., Mattera, M., Sanz, M.A. \& Bodoque, J.M. (2003). Hazard zoning for landslides connected to torrential floods in the Jerte Valley (Spain) by using GIS techniques. Natural Hazards, 361381. https://doi.org/10.1023/B:NHAZ.0000007171.13298.01

Cavalli, M., Crema, S., Trevisani, S., \& Marchi, L. (2017). GIS tools for preliminary debris-flow assessment at regional scale. Journal of Mountain Sciences, 14, 24982510. https://doi.org/10.1007/s11629-017-4573-y

Corominas, J. (1989). Estabilidad de taludes y laderas naturales. Clasificación y reconocimiento de los movimientos de ladera. Barcelona: Sociedad Española de Geomorfología.

Costa, J. E. (1984). Physical geomorphology of debris flows. In J.E. Costa \& P.J. Fleisher (Eds.), Developments and Applications of Geomorphology (pp. 268-317). Berlin: Springer.

Costa, M., Peris, J.E., Figuerola, R., \& Sttubing, O. (1985). Los alcornocales valencianos. Documents Phytosociologiques, 9, 301-308.

Coussot, P., \& Meunier, M. (1996). Recognition, classification and mechanical description of debris Flows. Earth-Science Reviews, 40, 209-227.

Deltoro, R. (2002). Marines. Historia de un Pueblo. València: Ayuntamiento de Marines.

Del Ventisette, C., Garfagnoli, F., Ciampalini, A., Battistini, A., Gigli, G., Moretti, S., \& Casagli, N. (2012). An integrated approach to the study of catastrophic debris-flows: Geological hazard and human influence. Natural Hazards and Earth System Sciences, 12, 29072922. https://doi.org/10.5194/nhess-12-2907-2012

Garay Martín, P. (2001). El dominio triásico Espadán-Calderona. Contribución a su conocimiento geológico e hidrogeológico (Doctoral dissertation, Universitat de València, Spain).

Garay-Martín, P. (2005). Unidades litoestratigráficas del Pérmico y Triásico Inferior en el Dominio Espadán-Calderona (Provincias de Castellón y Valencia). Geo-temas 8. In IV Coloquio de Estratigrafía y Paleogeográfía del Pérmico y el Triásico (pp. 155-158). Elx.

García-Fayos, P. (1991). La vegetación silicícola de la Sierra Calderona (Comunidad Valenciana). Lazaroa, 12, 317-332.

García Miralles, V., \& Carrasco, A. (1958). Lluvias de intensidad y extensión extraordinaria de las inundaciones de los días 13 y 14 de octubre de 1957 en las provincias de Valencia, Castellón y Alicante. Servicio Meteorológico Nacional, A-30 (pp. 1-67). 
García-Oteyza, J., Génova, M., Calvet, J., Furdada, G., Guinau, M., \& Díez-Herrero, A. (2015). Datación de avenidas torrenciales y flujos de derrubios mediante metodologías dendrogeomorfológicas (barranco de Portainé, Lleida, España). Ecosistemas 24(2), 43-50.

García-Ruiz, J.M., Arnáez, J., Ortigosa, L., \& Gómez Villar, A. (1988). Debris flows subsequent to a forest fire in the Najerilla River Valley (Iberian System, Spain). Pirineos, 131, 3-24.

García-Ruiz, J.M., Arnáez, J., Gómez-Villar, A., Ortigosa, L., \& Lana-Renault, N. (2013). Firerelated debris flows in the Iberian Range, Spain. Geomorphology 196, 221230. https://doi.org/10.1016/j.geomorph.2012.03.032

Giménez Font, P. (2006). Contexto geomorfológico y asentamiento humano: Abanicos aluviales y corrientes de derrubios en la sierra de Callosa (Bajo Segura, Alicante). In Geografía Física y Medio Ambiente (pp. 95-120). Alicante: Asociación de Geógrafos Españoles, Universidad de Alicante.

Gómez-Villar, A., Sanjuán, Y., García-Ruiz, J.M., Nadal-Romero, E., Álvarez-Martínez, J., Arnáez, J., \& Serrano-Muela, M.P. (2014). Sediment organization and adjustment in a torrential reach of the upper ljuez river, central Spanish Pyrenees. Cuadernos de Investigación Geográfica, 40(1), $191-214$

González-Herrero, S. (2018). Un octubre de récord. In El blog de la Agencia Estatal de Meteorología. Retrieved from https://aemetblog.es/2018/12/28/un-octubre-de-record/

Harvey, A.M. (1984). Debris Flows and Fluvial Deposits in Spanish Quaternary Alluvial Fans: Implications for Fan Morphology. Sedimentology of Gravels and Conglomerates, 10, 123-132.

Hermosilla Pla, J., \& Rodrigo Alfonso, C. (1997). Cambios de límites de términos municipales en el territorio valenciano por actuaciones del INC-IRYDA. Cuadernos de Geografía, 61, 61-75.

Hungr, O., Evans, S.G., Bovis, M., \& Hutchinson. J.N. (2001) Review of the classification of landslides of the flow type. Environmental and Engineering Geoscience, VII, 221-238.

Hürlimann, M., Abancó, C., Moya, J., \& Vilajosana, I. (2014). Results and experiences gathered at the Rebaixader debris-flow monitoring site, Central Pyrenees, Spain. Landslides, 11, 939953. https://doi.org/10.1007/s10346-013-0452-y

Hutchinson, J. N. (1968). Mass movement. In R.W. Fairbridge (Ed.), Encyclopedia of Geomorphology (pp. 688-695). New York, Reinhold. 
Inchaurrandieta, R. (1868). Conos de deyección en los torrentes. Revista de Obras Públicas, 16, 77-78 \& 89-91.

Iverson, R.M. (1997) The physics of debris flows. Reviews of Geophysics, 35(3), 245-296.

Johnson A. M., \& Rodine J.R. (1984). Debris flow. In D. Brunsden \& D.B. Prior (Eds.), Slope Instability (pp. 257-361). John Wiley \& Sons.

Lasanta, T., Beguería, S., \& García-Ruiz, J.M. (2006). Geomorphic and hydrological effects of traditional shifting agriculture in a Mediterranean mountain area, Central Spanish Pyrenees. Mountain Research and Development, 26(2), 146-152. https://doi.org/10.1659/02764741(2006)26[146:GAHEOT]2.0.CO;2

Las Provincias (1957a, October 17). Dramática situación en Marines. Las Provincias.

Las Provincias (1957b, October 22). Sesión extraordinaria del Pleno de la Diputación. Las Provincias.

Levante (1957a, October 18). De la Punta a Marines en helicóptero. Levante.

Levante (1957b, October 19). Marines en medio de la catástrofe. Levante.

Lorente, A., García-Ruiz, J. M., Beguería, S., \& Arnáez, J. (2002). Factors Explaining the Spatial Distribution of Hillslope Debris Flows. Mountain Research and Development, 22(1), 32-39.

Lütsch, O. (1926). Über Niederschlag und Abfliss im Hochgebirge Ein Beitrag zur Fluss- und Gletscherkunde der Schweiz, Schweizerischer Wasserwirtschaftsverband, Verbandsschrift Nr. 14. Zürich: Veröffentlichung der Hydrologischen Abteilung der Schweizerischen Meteorologischen Zentralanstalt in Zürich.

Madrazo, F. (1861). Inundaciones. Revista de Obras Públicas, IX, 81-86 \& 93-908 \& 105-114.

Marchi, L., \& Cavalli, M. (2007). Procedures for the documentation of historical debris flows: application to the Chieppena Torrent (Italian Alps). Environmental Management, 40(3), 493503, https://doi.org/10.1007/s00267-006-0288-5

Marco, J., \& Mateu, J. (2007). El fenómeno hidrológico. In ETSICCP (Coord.), Ciclo de Conferencias 50 años de la riada que transformó Valencia. Valencia, October 18-25 \& November 8-15.

Martínez-Castroviejo, R., \& García Ruiz, J.M. (1990). Coladas de piedras (debris flow) y dinámica fluvial en ríos torrenciales del Pirineo Central: El caso del rio ljuez. Cuadernos de Investigación Geográfica, 16, 55-72. 
Mougin, P. (1914). Les torrents de la Savoie. Grenoble: Grands Etablissements de I'Imprimerie Générale.

Mateu Bellés, J.F. (2018). Introducción de la teoría de los conos de deyección en España (18601890). In J.A. Márquez Domínguez \& R.M. Jordá Borrell (Eds.), Ciencia regional y Andalucía a partir de la visión del geógrafo Gabriel Marco Cano García: un homenaje a su vida y obra (pp. 299-315).

Mateu Bellés, J.F., Ruiz Pérez, J.M., Portugués Mollá, I., Carmona González, P., Bonache i Felici, X., \& Marco Segura, J.B. (2012). Materiales inéditos para el estudio de la riada del Turia en Valencia (octubre de 1957). Cuadernos de Geografía, 91-92, 181-196.

Olcina Cantos, J. (1999). Los temporales de octubre de 1957 en el levante español. Nimbus, 4, 129-152.

Pedraza, J., Carrasco, R. M., Bodoque, J. M., Sanz, M. A., Martín-Duque, J. F., González, A., \& Díez, A. (2004). The Jubaguerra stream event: analysis of a mass movement connected with a flash flood phenoment and its application to other areas in the Gredos Mountains (Central Spain). In C.A. Brebbia (Ed.), Risk Analysis IV. Wessex Institute of Technology (pp. 345-358). Southampton, United Kingdom: WIT Press.

Pereida, S., \& Zêzere, J.L. (2012). Empirically-based rainfall theresholds for debris flow occurrence in the north of Portugal. In XII Reunión Nacional de Geomorfología (pp. 109-112).

Pérez Cueva A. J. (1985). Geomorfología del sector oriental de la Cordillera Ibérica, entre los ríos. Mijares y Turia (Doctoral dissertation, Universitat de València, Spain).

Portugués, I., Bonache, X., Mateu, J.F., \& Marco, J.B. (2016). A GIS-Based Model for the analysis of an urban flash flood and its hydro-geomorphic response. The Valencia event of 1957. Journal of Hydrology, 541, 582-596. http://dx.doi.org/10.1016/j.jhydrol.2016.05.048

Procter, E., Stoffel, M., Schneuwly-Bollschweiler, M., \& Neumann, M. (2012). Earth Surface Processes and Landforms, 37, 913-922. https://doi.org/10.1002/esp.3207

Rodrigo, P. (1965). Enciclopedia del Tiempo. Barcelona: Ed. De Gasso Hnos.

Sánchez E., Gallardo C., Gaertner M.A., Arribas A., \& Castro M. (2004). Future climate extreme events in the Mediterranean simulated by a regional climate model: a first approach. Global Planetary Change, 44, 163-180. 
Santangelo, N., Santo, A., Di Crescenzo, G., Foscari, G., Liuzza, V., Sciarrotta, S., \& Scorpio, V. (2011). Flood susceptibility assessment in a highly urbanized alluvial fan: the case study of Sala Consilina (southern Italy). Natural Hazards and Earth System Sciences, 11, 27652780. https://doi.org/10.5194/nhess-11-2765-2011

Segura, F. (2003). Model d'inundacions en ventalls al.luvials: El cas de les planes costaneres valencianes. Cuadernos de Geografía, 73-74, 207-232.

Soler, A., \& Yago, R. (2004). Marines: geografía, historia, patrimonio. Marines: Ayuntamiento de Marines.

Surió, R., \& Cano, E. (1981). La muntanya de l'Aixavegó: un caso histórico de deslizamiento de grandes proporciones en la Ribera. Cuadernos de Geografía, 29, 151-160.

Surell, A. (1841) Etude sur les torrents des Hautes Alpes. Paris: Librairie des corps impériaux des ponts et chaussées et des mines.

Takahashi, T. (1981). Debris flow. Annual Review of Fluid Mechanics, 13, 57-77.

Takahashi, T. (2001). Process of occurrence, flow and deposition of viscous debris flow. In G. Seminara \& P. Blondeaux (Eds.), River, Coastal and Estuarine Morphodynamics (pp. 93-118). Springer-Verlag.

Takahashi, T. (2009). A Review of Japanese Debris Flow Research. International Journal of Erosion Control Engineering, 2, 1-14.

Tropeano, D., \& Turconi, L. (2004). Using Historical Documents for Landslide, Debris Flow and Stream Flood Prevention. Applications in Northern Italy. Natural Hazards, 31, 663679. https://doi.org/10.1023/B:NHAZ.0000024897.71471.f2

Varnes, D. J. (1954). Landslide types and processes. In E.B. Eckel (Ed.), Landslides and Engineering Practice (pp. 20-47). Washington, DC: Highway Research Board, National Academy of Sciences.

Varnes, D. J. (1978). Slope movement types and processes. In R.J. Schuster \& R.J. Krizek (Eds.), Landslides, Analysis and Control (pp. 11-33). Washington, DC.: Transportation Research Board, National Academy of Sciences.

White, S., García-Ruiz, J. M., Martí-Bono, C., Valero, B., Errea, M. P., \& Gomez-Villar, A. (1998). The 1996 Biescas campsite' disaster in the Central Spanish Pyrenees and its spatial and temporal context. Hydrological Processes, 11, 1797-1812. 